\section{DE LOS PALIATIVOS GLOBALES A LOS COMPROMISOS TERRITORIALES EN EL DEPARTAMENTO DEL TOLIMA. PLAN DE DESARROLLO "SOLUCIONES PARA LA GENTE 2008-2011"}

\author{
From The Global Palliatives To The Territorial Commitments In \\ Tolima State. Development Plan: "Solutions For The People \\ 2008-2011"
}

Miguel Antonio Espinosa Rico ${ }^{1}$

Palabras clave: Objetivos de Desarrollo del Milenio (ODM), desarrollo, compromisos territoriales, Departamento del Tolima

Keywords: Millennium Development Goals (MDG), Development, Territorial Commitments, Tolima State

\title{
Resumen.
}

El presente documento tiene por objeto ofrecer una lectura sobre las apuestas del gobierno del departamento del Tolima para el período 2008-2011, las cuales, aún sin proponérselo de manera explícita, recogen esfuerzos prospectivos realizados por administraciones anteriores, particularmente las orientadas por el Plan de Desarrollo 1990-1991 y Plan de Desarrollo 2001-2003, centrados los tres en población como sujeto insustituible de los ejercicios de planificación del desarrollo territorial. El presente mandato, cuyo eslogan "Soluciones para la gente", se bate diariamente entre las presiones de la politiquería tradicional y la franqueza del gobernador para reclamar compromisos y responsabilidad social a todos los actores de la vida territorial, ha aceptado los retos planteados por los Objetivos de Desarrollo del Milenio - ODM y al cumplimiento de sus metas e indicadores orienta la esencia de su intervención.

Una apuesta entre lo deseado y lo posible está en escena en el Tolima y más allá del final del cuatrienio, una evaluación de este balance deberá hacerse y con ella una contribución crítica al propósito mundial de superar la pobreza y la marginalidad.

\section{Abstract.}

This paper attempts to offer a reading on the proposals of the administration of state of Tolima for the period 2008-2011. These proposals are based on efforts done by previous administrations, particularly the ones directed by the Development Plan

1 M.Sc. Geógrafo. Subdirector Grupo de Estudios Urbano Regionales del Magdalena Medio - GEURM. Asesor de Asuntos Étnicos de la Gobernación del Tolima.

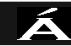

\section{F}

Año 15 Número 25,julio-diciembre de 2008 
1990-1991 and the Development Plan 2001-2003, all of them focused on population as irreplaceable subject of the planning practices for territorial development. The present local administration, who's slogan is "Solutions for the people", is debated every day between the pressures of the political traditional machinery and the frankness of the governor to claim commitments and social responsibility to all the actors of territorial life. This local administration has accepted the challenges raised by the Millennium Development Goals (MDG) and the fulfillment of its goals and indicators it faces which are the essence of its participation.

A proposal between the ideal contribution and the possible one is taking place in Tolima and beyond the end of the administration. An evaluation of this balance will have to be done in order to have a critical contribution to the world focus on overcoming poverty and marginality².

El desenvolvimiento de los ODM durante estos ocho años, nos ha dado elementos para identificar que ha habido dificultades al momento de responder a las problemáticas estructurales, que la dinámica de décadas atrás no ha variado mucho y aunque los mecanismos de intervención y la creación de redes han sido un avance innegable, no se puede dejar de lado que uno de los principales obstáculos ha sido la forma cómo se está abordando el propio tema. Cierto, el desarrollo se encuentra vigente en el mundo porque ha representado un proceso de mejora de condiciones para millones de seres humanos pero también representa un concepto vacío para quienes incansablemente lo han buscado y ante una mínima condición de vulnerabilidad lo pierden ¿No es un proceso que llega paulatinamente si todos los esfuerzos necesarios se coordinan? ¿Qué elementos fungen como mínimas condiciones para salir de condiciones que durante siglos han flagelado a grupos de pobres, indígenas, mujeres? Evidentemente la respuesta no es única porque el desarrollo es un concepto problema y no, un concepto solución ${ }^{3}$.

\section{Aspectos Generales}

El departamento del Tolima comprende una población de "1.365.342 habitantes", distribuida en 47 municipios, siendo los municipios de mayor población, Ibagué, la capital, con 495.246, Espinal con 75.375, Flandes con 27.683 y Melgar con 32.636, en el centro del departamento; Chaparral con 45.090, Guamo con 34.254 y Ortega con 33.297, en el sur y; Líbano con 41.650, Mariquita con 32.642, Fresno con 30.750, y Honda con 26.873, en el norte.

Según la información más actualizada (DANE, 2005), el departamento del Tolima cuenta con un $11 \%$ de población que está entre los 5 y los 9 años y los 10 y 14 años respectivamente, siendo el grupo poblacional más alto en el conjunto de la población tolimense. Estos datos permiten analizar y proyectar acciones que garanticen los derechos de la niñez y juventud, forjadores de la sociedad futura.

En orden descendiente el grupo poblacional entre los $0-4$ años tiene un $10 \%$ de participación en el total departamental son los niños, justificando una política de la primera infancia que comprende los niños y las niñas desde la gestación hasta llegar a los 5 años.

"Garantizar el ejercicio de los derechos de los niños y las niñas menores de 6 años, constituye el objetivo de la política pública orientada a la primera infancia. La garantía
2 Traducido por Jorge Enrique Jiménez, integrante grupo de investigación CITERM.-UAMRevisado por el nativo Kevin P. Guzzo.

3 MONROY, Marisol. Una aproximación crítica a la noción de desarrollo en la organización de naciones unidas: los Objetivos de Desarrollo del Milenio. México 2009

4 DANE. Censo 2005.

En la primera infancia se incluyen los niños y las niñas desde la gestación hasta llegar a los 5 años, pero sin haber alcanzado los 6 años

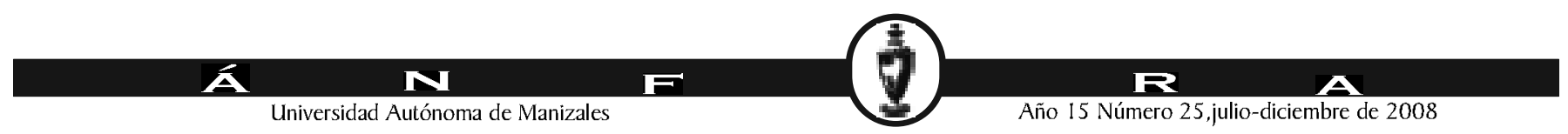


de los derechos, es indispensable para el desarrollo de la primera infancia y fundamental para elevar su calidad de vida."

En el ámbito nacional se está construyendo la Política de Primera Infancia ${ }^{5}$ lo cual debe ser un reflejo en el ámbito regional, dado que "es el Estado el directamente responsable de garantizar las condiciones materiales, jurídicas e institucionales para respetar, promover, cumplir y proteger los derechos de los niños y niñas en su conjunto, como prevalentes sobre los derechos de los demás, a través de mecanismos expeditos, construidos con criterios de accesibilidad, disponibilidad, permanencia y aceptabilidad social y cultural ${ }^{6 \prime \prime}$.

Las instituciones que conforman el comité técnico del Programa para la política de Primera Infancia son: "Banco Interamericano de Desarrolla BID, CERLALC, CINDE, Departamento Administrativo de Bienestar Social DABS, Departamento Nacional de Planeación DNP, Fondo para la Acción Ambiental y la Niñez, Instituto Colombiano de Bienestar Familiar ICBF, Ministerio de Educación Nacional, Ministerio de Protección Social, Organización Panamericana de la Salud OPS, Plan Internacional, Pontificia Universidad Javeriana, Save the Children, Universidad de Manizales, Universidad Nacional de Colombia, Universidad Pedagógica Nacional, UNICEF, Visión Mundial".

Con un porcentaje menor a 9\% por ciento encontramos a los jóvenes entre los 15 y 19 años, seguidos por el grupo entre los 25 y 29 años con un 7\%, y por debajo de este indicador y orden ascendente, los grupos entre los 30-34, 35 y 39, 40 y 44, y 65 años y mas cada uno con un $7 \%$ respectivamente. Los demás rangos como se observa en la tabla tienen baja participación en el conjunto de la población tolimense.

Cuadro 1. Tolima. Población Por Rangos De Edad Según Dane 2005

\begin{tabular}{|l|l|l|}
\hline Rango & No habita & $\%$ \\
\hline $0-4$ & 128.636 & 10 \\
\hline $5-9$ & 143.999 & 11 \\
\hline $10-14$ & 146.835 & 11 \\
\hline $15-19$ & 122.579 & 9 \\
\hline $20-24$ & 98.673 & 7 \\
\hline $25-29$ & 104.343 & 8 \\
\hline $30-34$ & 86.878 & 7 \\
\hline $35-39$ & 88.487 & 7 \\
\hline $40-44$ & 87.968 & 7 \\
\hline $45-49$ & 75.123 & 6 \\
\hline $50-54$ & 66.673 & 5 \\
\hline $55-59$ & 51.783 & 4 \\
\hline $60-64$ & 42.623 & 3 \\
\hline 65 y mas & 90.572 & 7 \\
\hline Total & 1.335 .172 & 100 \\
\hline
\end{tabular}

Fuente: DANE 2005.

5 En la primera infancia se incluyen los niños y las niñas desde la gestación hasta llegar a los 5 años, pero sin haber alcanzado los 6 años

6 República de Colombia, "Colombia por la primera infancia, Política Pública por los niños y niñas, desde la gestación hasta los 6 años". Bogotá, diciembre de 2006.

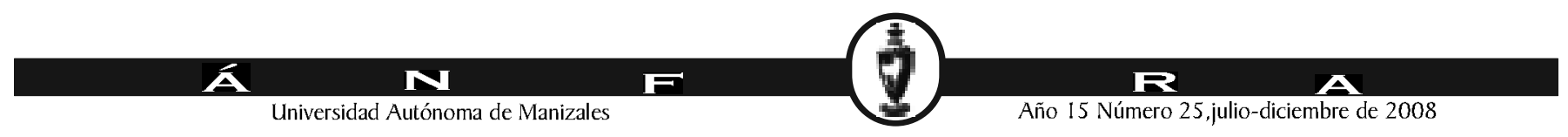




\section{Población urbana y rural}

Al nivel mundial existe una marcada preocupación por la transformaciones que ha venido sufriendo el campo y las ciudades, y que se percibe en el informe sobre «Estado del Mundo 2007: Nuestro futuro urbano», elaborado por el Instituto Worldwatch quien manifiesta que "Hace sólo un siglo, la gran mayoría de la población mundial vivía en áreas rurales -en 1900 sólo un 10 por ciento de la población habitaba las ciudades-, pero en algún momento del próximo año esta situación se revertirá y serán más los que habiten las urbes que los pueblos".

El departamento del Tolima es la muestra más clara de esta situación mundial con gran incidencia local. Se presentan permanentes migraciones de la población campesina hacia centros poblados como Ibagué, Espinal, Honda, Mariquita, Fresno, Lérida, Melgar, Ortega, Chaparral, entre otros, a causa del conflicto interno armado; la violación de derechos humanos; la falta de una política agraria y las graves consecuencias de la pugna territorial entre actores armados.

Son múltiples las causas por las cuales la población debe emigrar, alterando la dinámica social, económica y política, del país, del departamento y de la región. Las amenazas, las masacres, los asesinatos, los enfrentamientos entre actores armados que afectan a la población y sus bienes, las desapariciones forzadas, el miedo y la pugna político institucional, además de la pobreza de la población rural, han sido las causas más frecuentes de desplazamiento y migración.

En el año 2005 según el censo DANE el 66\% de población departamental esta ubicada en las cabeceras urbanas y el $34 \%$ en el sector rural, lo cual confirma lo planteado.

El cuadro № 2 muestra los municipios según porcentajes de población urbana y rural, con base en el Censo DANE 2005. (ver cuadro)

La posición geopolítica del Tolima es privilegiada por su ubicación en el centro del país, su capital I bagué está separada por sólo 201 Kms de Bogotá, capital de Colombia, y comunicada, con las regiones Caribe y Pacífico, por una red de carreteras nacionales, que conectan a las principales ciudades y puertos del país y del exterior.

El territorio tolimense es rico en recursos naturales, fuentes de agua y paisajes de ensueño. Al Tolima pertenece la mayor parte del Parque Nacional de Los Nevados ubicado en el norte del departamento sobre la cordillera Central (aprox. 66\% del área total $^{7}$ ), haciendo de límite con los departamentos de Caldas, Risaralda y Quindío. En la misma cordillera Central, en el sur, se ubican el Parque Natural Nacional Páramo de las Hermosas y el Parque Natural Nacional Nevado del Huila, perteneciente al Complejo Macizo Colombiano, singulares piezas de los recursos hídricos y de la inimaginable biodiversidad del departamento y del país. En las estribaciones de la Cordillera Oriental, sobre los pliegues de sus faldas, un sin fin de sierras, cavernas, cascadas, puentes naturales, ríos y lagunas. El territorio tolimense es regado por el río Magdalena y por importantes afluentes como los ríos Saldaña, Coello, Recio, Lagunilla, Gualí y Guarinó.

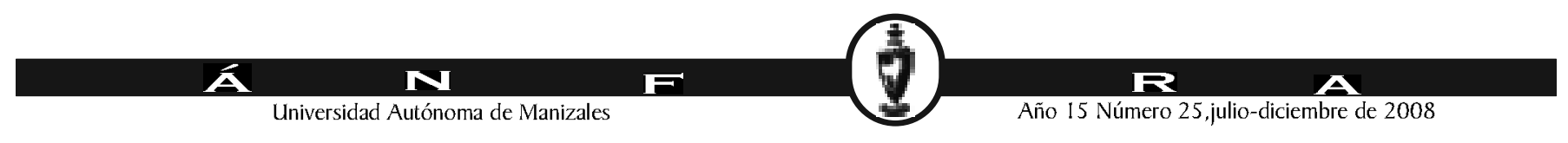


Cuadro 2. Tolima. Población Total Según Áreas Urbana Y Rural 1951 -2005

\begin{tabular}{|c|c|c|c|c|c|c|c|c|c|c|c|c|}
\hline \multirow{2}{*}{\begin{tabular}{|l|l} 
& \\
\end{tabular}} & \\
\hline & \multicolumn{2}{|c|}{1951} & \multicolumn{2}{|c|}{1964} & \multicolumn{2}{|c|}{1973} & \multicolumn{2}{|c|}{1985} & \multicolumn{2}{|c|}{1993} & \multicolumn{2}{|c|}{2005} \\
\hline & Urbano & Rural & Urbano & Rural & Urbano & Rural & Urbano & Rural & \begin{tabular}{|l|} 
Urbano \\
\end{tabular} & Rural & Urbano & Rural \\
\hline IBAGUE & 54,347 & 44,348 & 125,233 & 38,428 & 202,850 & 27,164 & 288,575 & 26,379 & 371,274 & 28,564 & 465,859 & 29,387 \\
\hline Alpujarra & 1,091 & 5,063 & 1,744 & 5,575 & 2,950 & 4,543 & 1,652 & 4,764 & 1,669 & 3,659 & 1,805 & 3,293 \\
\hline Alvarado & 789 & 8,176 & 1,451 & 6,741 & 2,230 & 7,087 & 1,880 & 7,335 & 2,350 & 5,990 & 3,138 & 5,735 \\
\hline Ambalema & 4,576 & 4,044 & 5,438 & 3,053 & 5,976 & 3,223 & 5,398 & 3,114 & 5,997 & 2,144 & 5,730 & 1,833 \\
\hline Anzoategui & 1,138 & 12,656 & 2,273 & 8,670 & 3,180 & 7,027 & 1,894 & 8,845 & 1,914 & 9,097 & 2,016 & 14,530 \\
\hline Armero & 10,258 & 10,412 & 17,495 & 9,239 & 20,701 & 8,060 & 2,433 & 23,186 & 9,038 & 5,827 & 8,745 & 4,107 \\
\hline Ataco & 1,511 & 16,100 & 3,304 & 11,243 & 3,653 & 16,337 & 3,161 & 21,045 & 4,084 & 18,810 & 4,566 & 17,037 \\
\hline Cajamarca & 4,640 & 14,303 & 6,188 & 10,759 & 6,877 & 9,491 & 7,694 & 11,631 & 8,486 & 12,551 & 9,264 & 10,237 \\
\hline $\begin{array}{l}\text { Carmen de } \\
\text { A }\end{array}$ & 1,495 & 2,737 & 3,107 & 2,525 & 2,496 & 2,393 & 2,934 & 2,299 & 4,551 & 2,275 & 6,248 & 2,082 \\
\hline Casabianca & 961 & 6,694 & 2,037 & 6,215 & 1,959 & 5,717 & 1,594 & 5,951 & 1,611 & 5,788 & 1,478 & 5,315 \\
\hline Chaparral & 11,705 & 25,125 & 13,261 & 16,560 & 15,365 & 25,329 & 19,715 & 28,657 & 22,924 & 23,842 & 25,134 & 20,956 \\
\hline Coello & 879 & 8,225 & 629 & 10,644 & 1,274 & 8,953 & 919 & 8,956 & 930 & 6,664 & 1,531 & 7,409 \\
\hline Coyaima & 959 & 15,963 & 1,721 & 16,403 & 1,657 & 22,186 & 2,856 & 24,633 & 3,163 & 23,953 & 4,224 & 23,509 \\
\hline Cunday & 1,679 & 17,451 & 2,895 & 14,936 & 2,512 & 15,928 & 2,334 & 13,176 & 2,380 & 10,799 & 2,282 & 6,163 \\
\hline Dolores & 2,305 & 7,402 & 3,324 & 5,927 & 3,789 & 6,146 & 4,404 & 7,693 & 4,481 & 6,548 & 3,206 & 5,063 \\
\hline Espinal & 9,389 & 24,818 & 22,791 & 21,101 & 34,681 & 9,938 & 40,733 & 17,963 & 47,602 & 24,110 & 55,329 & 20,046 \\
\hline Falan & 1,242 & 14,690 & 848 & 20,265 & 1,783 & 12,242 & 2,448 & 13,958 & 4,735 & 14,763 & 1,659 & 6,264 \\
\hline Flandes & & & 12,015 & 4,511 & 15,749 & 4,745 & 18,417 & 4,376 & 21,086 & 3,620 & 23,484 & 4,199 \\
\hline Fresno & 5,019 & 16,725 & 7,058 & 16,654 & 9,233 & 13,571 & 10,848 & 16,721 & 14,099 & 20,314 & 14,268 & 16,462 \\
\hline Guamo & 4,645 & 19,877 & 8,350 & 22,488 & 12,014 & 14,780 & 14,128 & 22,162 & 15,640 & 21.77 & 16,163 & 18,091 \\
\hline Herveo & 1,402 & 10,059 & 2,313 & 9,902 & 2,304 & 8,405 & 1,995 & 8,485 & 2,936 & 8,878 & 2,205 & 6,696 \\
\hline Honda & 16,051 & 1,574 & 19,995 & 1,728 & 22,847 & 2,584 & 26,753 & 1,132 & 29,283 & 853 & 25,991 & 882 \\
\hline Icononzo & 1,614 & 7,318 & 2,389 & 11,446 & 2,536 & 9,099 & 2,715 & 8,692 & 3,258 & 8,743 & 3,293 & 6,837 \\
\hline Lerida & 2,756 & 8,016 & 3,827 & 5,543 & 3,542 & 6,721 & 11,084 & 4,693 & 14,917 & 7,115 & 13,977 & 4,138 \\
\hline Libano & 12,090 & 30,890 & 18,640 & 35,934 & 19,880 & 21,291 & 25,267 & 16,323 & 28,817 & 15,834 & 25,772 & 15,878 \\
\hline Mariquita & 6,066 & 7,165 & 9,573 & 8,341 & 11,706 & 6,799 & 16,696 & 9,361 & 20,645 & 9,571 & 23,376 & 9,266 \\
\hline Melgar & 1,069 & 4,908 & 3,385 & 5,108 & 5,748 & 5,330 & 11,747 & 5,016 & 19,528 & 4,986 & 26,738 & 5,898 \\
\hline Murillo & & & & & 2,208 & 1,108 & 2,034 & 3,841 & 2,016 & 4,248 & 1,569 & 3,384 \\
\hline Natagaima & 4,107 & 12,463 & 8,372 & 10,731 & 8,497 & 9,579 & 9,279 & 10,799 & 9,228 & 15,224 & 13,499 & 6,769 \\
\hline Ortega & 2,874 & 26,510 & 4,450 & 17,210 & 4,815 & 27,536 & 5,083 & 30,349 & 6,118 & 30,303 & 7,530 & 25,767 \\
\hline Palocabildo & & & & & & & & & & & 2,654 & 6,779 \\
\hline Piedras & 1,505 & 4,144 & 924 & 4,364 & 1,658 & 3,191 & 1,359 & 4,557 & 1,266 & 3,689 & 1,612 & 3,758 \\
\hline Planadas & & & 2,139 & 5,966 & 4,145 & 13,049 & 4,426 & 17,981 & 6,537 & 22,914 & 7,146 & 21,662 \\
\hline Prado & 1,319 & 6,503 & 1,817 & 5,495 & 2,452 & 6,434 & 2,821 & 7,599 & 3,611 & 6,946 & 3,426 & 5,179 \\
\hline Purificacion & 4,976 & 19,190 & 7,044 & 15,336 & 8,609 & 14,736 & 9,180 & 15,084 & 11,012 & 14,109 & 15,587 & 11,999 \\
\hline rioblanco & 770 & 6,650 & 1,689 & 9,771 & 1,897 & 13,605 & 2,369 & 24,785 & 3,862 & 28,441 & 4,269 & 20,724 \\
\hline Roncesvalles & 849 & 5,576 & 894 & 3,428 & 1,236 & 3,621 & 1,460 & 4,320 & 2,829 & 5,624 & 1,727 & 4,363 \\
\hline Rovira & 3,939 & 17,722 & 4,582 & 9,425 & 5,423 & 17,157 & 7,237 & 17,823 & 7,537 & 16,762 & 9,391 & 11,859 \\
\hline Saldaña & & & 3,195 & 3,712 & 4,595 & 6,020 & 6,532 & 7,166 & 7,936 & 8,253 & 8,207 & 6,525 \\
\hline San Antonio & 2,985 & 11,444 & 3,005 & 9,466 & 4,073 & 11,356 & 4,856 & 14,463 & 5,280 & 13,461 & 4,352 & 10,618 \\
\hline San Luis & 1,488 & 8,214 & 2,391 & 10,623 & 4,371 & 10,455 & 3,010 & 12,436 & 3,335 & 14,063 & 3,663 & 9,784 \\
\hline Santa Isabel & 1,942 & 7,439 & 2,489 & 5,645 & 2,293 & 2,593 & 2,190 & 5,521 & 2,281 & 4,777 & 2,235 & 4,218 \\
\hline Suarez & 842 & 4,229 & 1,099 & 3,464 & 1,383 & 3,456 & 1,579 & 3,222 & 1,333 & 2,765 & 1,938 & 2,534 \\
\hline Valle de SJ & 1,268 & 6,666 & 1,855 & 2,832 & 1,512 & 4,360 & 1,650 & 4,401 & 1,645 & 3,894 & 2,490 & 3,641 \\
\hline Venadillo & 4,784 & 10,556 & 6,931 & 6,413 & 9,162 & 6,575 & 8,372 & 7,190 & 11,313 & 5,595 & 13,208 & 5,368 \\
\hline V.Hermosa & 1,734 & 12,465 & 2,625 & 9,828 & 3,359 & 11,323 & 3,762 & 7,681 & 3,325 & 10,681 & 3,399 & 7,520 \\
\hline Villarica & 2,198 & 10,724 & 2,810 & 8,231 & 2,719 & 9,391 & 2,766 & 6,219 & 3,100 & 6,354 & 2,306 & 3,704 \\
\hline TOTAL & 142,909 & 470,886 & 234,362 & 433,451 & 291,049 & 433,470 & 321,664 & 505,604 & 389,688 & 474,837 & 887,689 & 447,468 \\
\hline$\%$ & 23.3 & 76.7 & 35.1 & 64.9 & 40.2 & 59.8 & 38.9 & 61.1 & 45.1 & 54.9 & 66.5 & 33.5 \\
\hline
\end{tabular}




\section{Agudas desigualdades espaciales del desarrollo}

La consolidación de modelos de desarrollo extractivos durante la colonia, basados primero en el trabajo de población indígena y africana esclavizada (siglos XVI, XVII y XVIII); continuados por sistemas de aparcería, colonización y trabajo asalariado en condiciones miserables entre los Siglos XIX y el presente, han caracterizado la base de la economía colombiana que enorgullece a los economistas del establecimiento, pero que oculta la realizad de una estructura productiva atrasada y porcentualmente más primaria que la que existió durante la colonia.

Los escasos sectores modernos de la economía son aquellos que están articulados a la maquila dependiente de las trasnacionales y al sector comercial de grandes superficies, mercado de franquicias de oferta de bienes comerciales, sector de las comunicaciones y finanzas, éstos últimos dependientes abrumadoramente de consorcios internacionales y en los cuales la participación del capital nacional está ausente o es insignificante.

Al producirse la concentración urbana y de tierras rurales, forzadas por acciones perversas de expropiación de tierras a campesinos y colonos, en el campo, y de monopolio del suelo urbano, en las ciudades, se constituyó un mecanismo particular en Latinoamérica en el que la relación campo - ciudad expresa el fenómeno patológico de pobreza - riqueza, presente en los dualismos antagónicos e irracionales de este modelo de desarrollo.

De esta manera, las áreas que concentran hoy en día la riqueza no son muy distantes de los que se proyectaron desde la colonia. Sin embargo es el rasgo del modelo lo que importa observar. Un modelo centrífugo en el que los grandes y medianos centros urbanos crecen a expensas del empobrecimiento de sus áreas rurales circundantes, de las cuales han tomado primero las riquezas de la naturaleza y después la riqueza material que puede producir su gente, incluida la misma gente, atraída sin remedio a la ciudad, ya por la crisis insostenible de la economía agraria, ya por el cerco impuesto por la pobreza creciente que amenaza con violencia física o sin ella la supervivencia de las nuevas generaciones.

Los dos últimos siglos de la historia de Colombia muestran la consolidación de un modelo en el que sobresale la dualidad regiones ricas - regiones pobres, como el reflejo más evidente del fracaso de todos los gobiernos y el anuncio de crisis acumuladas que constituyen la principal causa de la desestabilización presente de un sistema de democracia pervertido y apenas reproductor de marginalidad, exclusión, pobreza y violación de derechos humanos.

El panorama socioeconómico del Tolima muestra hechos preocupantes relacionados con lo antes expuesto:

$\varnothing$ Contrastan las áreas deprimidas cafeteras de las cordilleras, con la expansión de una ganadería extensiva en el valle del Magdalena, que ha ido reemplazando la activa producción agrícola tecnificada, eliminada por las políticas aperturistas del gobierno nacional.

$\varnothing \quad$ El cierre sistemático de pequeñas plantas industriales y agroindustriales en las ciudades de Honda, Mariquita, Venadillo, Ibagué, Espinal, Guamo, Saldaña, contrastan con el florecimiento de establecimientos comerciales de grandes

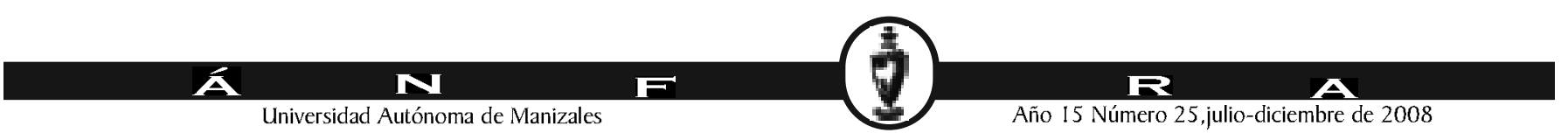


supermercados en la Capital y del capital parasitario financiero, por cuyo mandato se liquidaron desde el gobierno central proyectos promisorios de economía solidaria y de la pequeña y mediana empresa regional.

$\varnothing$ El crecimiento del desplazamiento forzado, en plena aplicación de la política de "seguridad democrática" contrasta con el crecimiento de barrios marginales en las ciudades de Honda, Mariquita, Líbano, Lérida, Ibagué, Espinal, Melgar y Chaparral, todos ellos habitados por familias que proceden de municipios del Tolima pero también de todas las regiones del país más afectadas por la violencia contemporánea.

$\varnothing \quad$ La inversión del presupuesto nacional está centralizada en los macroproyectos de interés del capital trasnacional, como la doble calzada BogotáBuenaventura, la generación hidroeléctrica, los nodos de apoyo logístico y los distritos de riego, pero son cada día menores los aportes para proyectos de inversión orientados a la reactivación de la producción agropecuaria e industrial nacional, con lo que la mano de obra cesante por la crisis agraria se suma a la ya crítica situación del desempleo urbano, del cual Ibagué, es la ciudad que registra las más altas tasas de desempleo del país durante los últimos cinco años consecutivos.

$\varnothing$ Los sectores más marginados del progreso en el departamento no han dejado de ser escenarios de la confrontación armada entre la insurgencia y el Estado por el control territorial y no cesan los desplazamientos forzados y la amenaza latente contra la población civil no combatiente.

\section{Actividad Económica ${ }^{8}$}

\section{Una década perdida.}

Hace una década, desde 1997, una nueva realidad social y económica se presenta en el escenario del Tolima. Coincidente con la crisis de crecimiento del país de finales de la década pasada, la riqueza generada por el Tolima en su conjunto, el PIB regional medido en valores constantes, se estanca. El Tolima lleva una década en la cual su generación de nueva riqueza se acerca a cero.

Desde entonces el producto medido a pesos constantes deja de crecer; el crecimiento

Granca 1

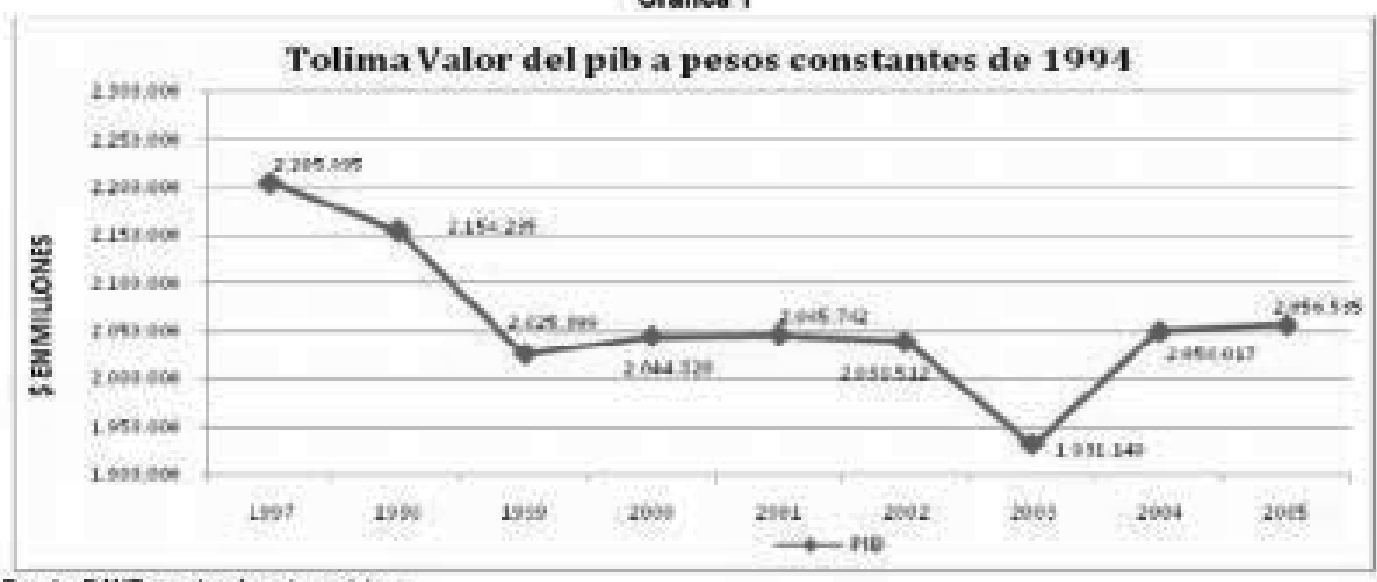

8 Plan de Desarrollo "Soluciones para la gente 2008-2011".

Fuente. DANE cuerias departamentales

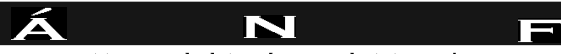

Universidad Autónoma de Manizales 
de la población hace descender el PIB per capita, la participación del Tolima en la riqueza generada por la nación decrece, comienza una etapa de agudo desempleo que no se modera a través de la década aunque el país en su conjunto tienda a disminuir la tasa principalmente desde los inicios del nuevo siglo. En nueve de los últimos diez años la tasa de crecimiento interanual del PI B del Tolima es negativa o igual a cero.

Grafica 2

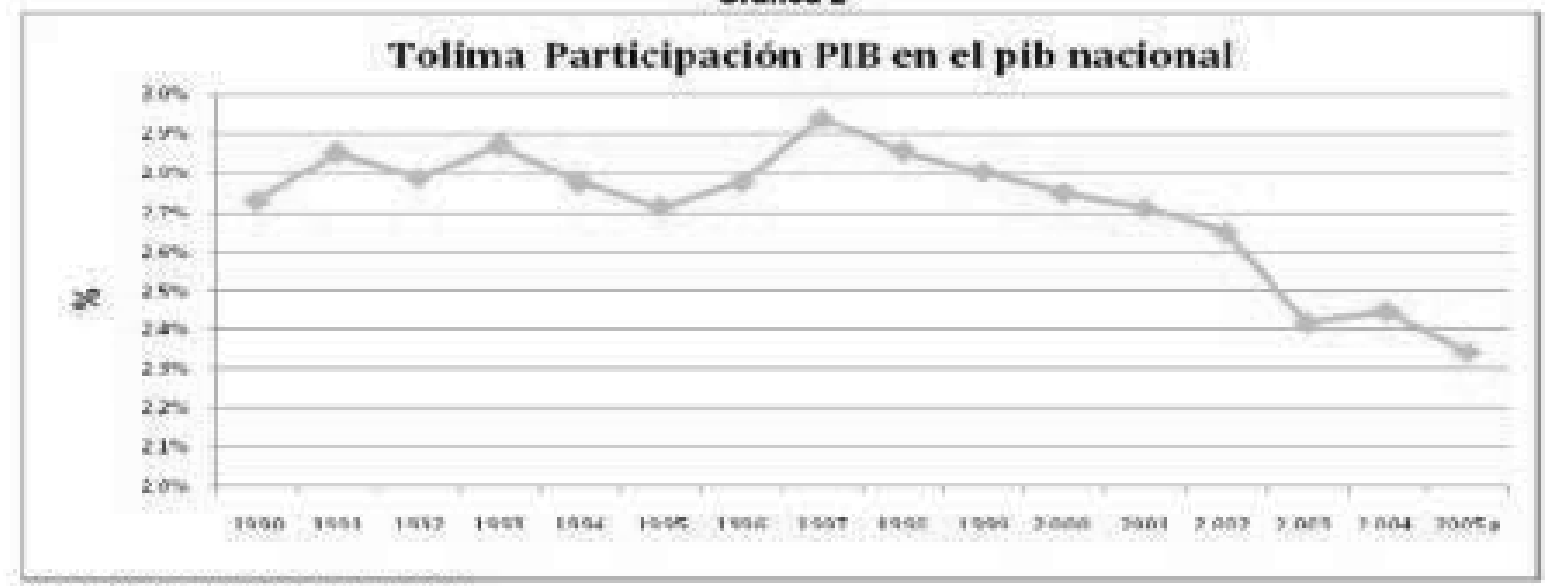

Fuente. DANE cuentas departamentalss

Múltiples causas se han atribuido para explicar la génesis de esa situación: La crisis económica de la nación entre 1997 y 2000, la contracción del sector financiero y cooperativo de 1998 y 1999, la terminación de los beneficios fiscales destinados a superar el desastre de Armero y el retiro de muchas empresas instaladas para aprovecharlos, las dificultades de muchas empresas que se acogieron a la ley 550 cerraron, el declive de la construcción entre 1993 y 2000, los precios del café y el inicio de la disminución de las áreas sembradas y el deterioro de los cultivos por baja rentabilidad, el declive de algunos productos agrícolas, y otros. Todas ellas convergieron en ese lapso y en conjunto explican el comportamiento de nuestra economía en los anos primeros de la crisis.

En el periodo se produce la desindustrialización de Ibagué: el cierre de plantas industriales atraídas por los beneficios fiscales paliativos de la tragedia de Armero y de otros negocios, lo cual hace que el empleo industrial caiga hasta abarcar apenas a 7.068 personas en calidad de ocupadas por el sector. Esta situación coincide en el tiempo con una aguda crisis agrícola y recientemente la inserción de la economía colombiana a la economía internacional a través de los tratados internacionales de comercio plantea al sector nuevas inquietudes.

La agudeza de la crisis se refleja en algunas cifras: Seis actividades productivas que en conjunto representaban cerca del $30 \%$ del PIB entran en crisis, la construcción ocupó en 1990 a 10.744 personas, en el año 1995 a 16.096 y en el año 2002 a solo 7.546 trabajadores; el sector financiero paso de emplear 5.831 trabajadores en 1990 a 12.492 empleos en 1994 y a 2145 personas en el año 2002, en 1990 el Tolima contaba con 41 oficinas de instituciones financieras, correspondientes a 14 bancos, 5 corporaciones financieras, 10 corporaciones de ahorro y vivienda y 3 entidades

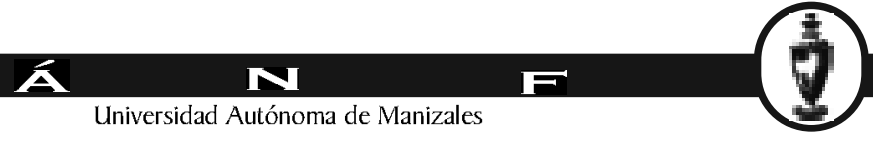



niveles de educación causada por la imposibilidad de pagar los estudios de sus hijos y estos se incorporan al mercado laboral, por cada individuo que pierde el trabajo una o más personas de la familia comienzan a buscar empleo y abandonan los estudios o los oficios domésticos, la oferta de la Universidad Pública de bajo costo es insuficiente y pocas familias pobres pueden cubrir matriculas en universidades privadas. Esa búsqueda de empleo es infructuosa, ya que el desempleo de los jóvenes es mayor que en los adultos y el problema es más grave en las mujeres jóvenes. Todo contribuye a crear un mercado laboral congestionado por personas que normalmente deberían estar en etapa de capacitación.

La estructura económica se muestra incapaz de absorber la masa laboral sobrecargada por jóvenes con niveles de educación y capacitación laboral insuficientes para ocuparse en condiciones dignas.

\section{Grafica 4}

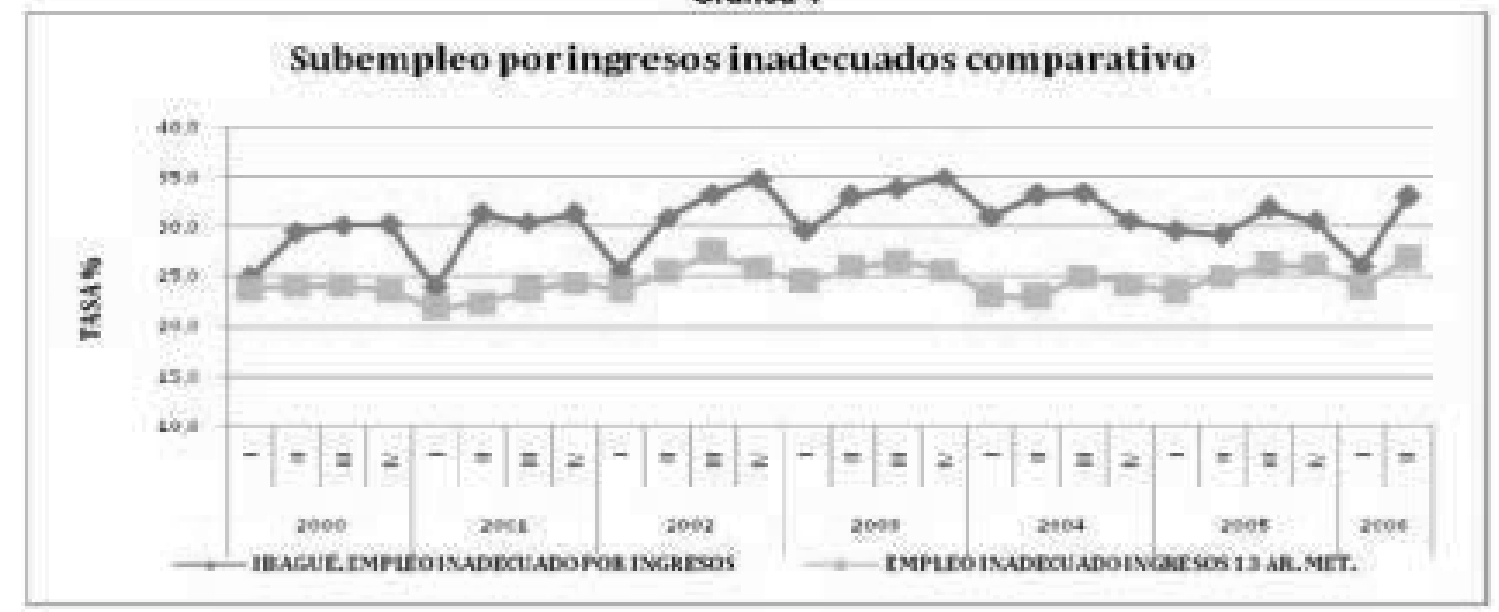

Los datos y análisis mostrados para I bagué influyen de manera importante en el marco del departamento, cuyos índices son menos alarmantes que para la capital departamental, pero sobresalen en el nivel nacional como altos en desempleo. No puede esperarse cosa diferente dada la alta participación de I bagué en la población del Tolima. Por ejemplo la tasa global de participación del Tolima es la quinta en el país. La siguiente tabla permite dar indicaciones sobre la situación del Tolima en su conjunto en aspectos laborales. Los datos y análisis mostrados para I bagué influyen de manera importante en el marco del departamento, cuyos índices son menos alarmantes que para la capital departamental, pero sobresalen en el nivel nacional como altos en desempleo. No puede esperarse cosa diferente dada la alta participación de I bagué en la población del Tolima. Por ejemplo la tasa global de participación del Tolima es la quinta en el país. La siguiente tabla permite dar indicaciones sobre la situación del Tolima en su conjunto en aspectos laborales. (ver tabla 1)

De ella se infiere: Un porcentaje mayor de personas en edad de trabajar que supera en $0,6 \%$ al iniciar el periodo en análisis y en $1,2 \%$ al año 2005; una mayor tasa de participación para el Tolima, una tasa de desempleo superior en todos los años, un desempleo abierto mayor en el Tolima, un subempleo por ingresos más alto para el Tolima, en años hasta de $10 \%$ superior. Ante las dificultades de obtener empleo formal se recurre entonces a la informalidad como solución temporal de la falta de ocupación y carencia de ingresos.

\section{E N} Universidad Autónoma de Manizales 
Tabla 1

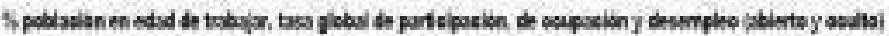

\begin{tabular}{|c|c|c|c|c|c|c|c|c|c|c|}
\hline ates & 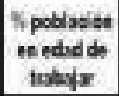 & 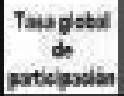 & $\begin{array}{l}\text { Tra de } \\
\text { otupieition }\end{array}$ & $\begin{array}{l}\text { Thas de } \\
\text { teserpint }\end{array}$ & TD. Abiats & to Oatho & $\begin{array}{l}\text { Tasa on } \\
\text { suberies }\end{array}$ & $\begin{array}{l}\text { Imifintuntia dt } \\
\text { Meris }\end{array}$ & Erplos invideceats por & $\begin{array}{c}\text { Enples } \\
\text { nodesuado } \\
\text { poringreses }\end{array}$ \\
\hline \multicolumn{11}{|c|}{ Tolina } \\
\hline 201 & 789 & 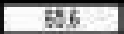 & $B 2$ & 139 & 127 & 2.2 & 355 & 702 & 20 & 23.3 \\
\hline 20 & $\pi \mu$ & 69 & 525 & 176 & 101 & 7,7 & $4: 7$ & 20 & 24 & $\overline{\mathrm{g} t}$ \\
\hline 2025 & 769 & 518 & 023 & 180 & TEE & 1,5 & 392 & 34 & 27 & 34 \\
\hline 2924 & 7.4 & E5 & E25 & 169 & 155 & 1,2 & $\$ 02$ & $\sqrt{22}$ & 27 & $\$ 22$ \\
\hline 305 & $7 \pi 8$ & $\$ 10$ & 324 & 140 & 122 & DI & 34 & 15,5 & 24 & 276 \\
\hline & & & & & & & & & & \\
\hline \multicolumn{11}{|c|}{ Toud Hatona } \\
\hline $20 \pi$ & 753 & 819 & 525 & 150 & 129 & 1.3 & 35 & 241 & 31 & 252 \\
\hline 202 & $\overline{R, 6}$ & 513 & $\mathrm{Btg}$ & 155 & 142 & $\overline{t, 1}$ & अक & $\$ 40$ & 30 & 277 \\
\hline 2000 & 58,9 & 823 & 35 & $14 !$ & (213) & 1,1 & 35 & 127 & 31 & हो? \\
\hline 34 & $\pi, 3$ & 65 & 515 & 136 & 75 & $t, 1$ & 311 & 120 & 32 & 253 \\
\hline 2005 & TE5 & 899 & $\mathbb{B 2 3}$ & HII & $12 !$ & 0.3 & $3+4$ & $\pi 4$ & 33 & 29 \\
\hline
\end{tabular}

Fuarie: OAWE, Encuesta contras de hogares

\section{Sectores históricamente marginados}

En este marco de referencia resultan evidentes y observables los sectores del territorio nacional y departamental que acumulan olvido gubernamental y que en el caso del Tolima no pueden ser otros que aquellos donde la confrontación por la tierra ha sido el motivo principal de procesos de asentamiento humano.

En este orden de ideas, el primero de estos sectores es el sur del Tolima, territorio de la más vasta, vergonzosa y aberrante campaña de exterminio de pueblos indígenas que vivió Colombia en toda su historia. De no menos de 70 pueblos existentes a la llegada de los españoles, apenas los pueblos Coyaima y Natagaima lograron sobrevivir al etnocidio comandado por los españoles y acompañado de manera cómplice por las elites regionales.

El segundo sector es el Sumapaz, donde la disputa por el control territorial enfrentó a colonos y campesinos pobres con terratenientes y latifundistas amparados por el gobierno.

El tercer sector, igual que el Sumapaz, es el norte cordillerano, donde a la colonización antioqueña y cundiboyacense sucedió una lucha permanente por la tierra, contenida por el cerco de la propiedad terrateniente ya desde la colonia establecida en las fértiles tierras del Valle del Magdalena.

Los centros de "desarrollo económico" aparecen así en toda su magnitud: Honda, Mariquita, Líbano, Armero, al norte; Ibagué, Espinal, Guamo, Melgar, en el centro; Purificación, en el oriente y; Chaparral, en el sur.

Al respecto los indicadores de Necesidades Básicas Insatisfechas - NBI del Censo Nacional de Población y Vivienda de 2005, muestran que las tasas de NBI en los municipios sureños de Ortega, San Luis, Coyaima, Natagaima, Ataco, Rioblanco y Planadas oscilan entre el 51 y más del $70 \%$, situándose entre las más altas del país.

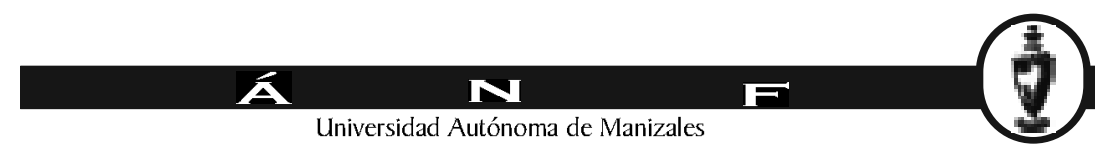


Cuadro 3. Tolima. NBI Por Municipios y Áreas 2005

\begin{tabular}{|c|c|c|c|}
\hline & Cabecera & & \\
\hline Municipios & $\%$ & Resto \% & NBI Total \% \\
\hline Ibagué & 14.84 & 37.60 & 16.20 \\
\hline Alpujarra & 28.80 & 44.92 & 39.31 \\
\hline Alvarado & 33.08 & 52.89 & 45.84 \\
\hline Ambalema & 34.92 & 31.50 & 34.09 \\
\hline Anzoátegui & 27.12 & 44.67 & 40.47 \\
\hline Armero-Guayabal & 29.82 & 38.61 & 32.63 \\
\hline A taco & 43.96 & 75.58 & 66.37 \\
\hline Cajamarca & 20.30 & 35.57 & 28.34 \\
\hline Carmen de Apicalá & 24.96 & 39.73 & 28.66 \\
\hline Casabianca & 18.65 & 36.18 & 32.55 \\
\hline Coello & 37.61 & 46.88 & 45.30 \\
\hline Coyaima & 36.35 & 77.98 & 71.64 \\
\hline Cunday & 25.58 & 46.10 & 40.60 \\
\hline Chaparral & 26.48 & 72.35 & 47.46 \\
\hline Dolores & 34.18 & 59.92 & 45.32 \\
\hline Espinal & 22.03 & 43.49 & 27.84 \\
\hline Falan & 24.03 & 38.93 & 35.85 \\
\hline Flandes & 19.05 & 34.85 & 21.45 \\
\hline Fresno & 19.20 & 35.92 & 28.20 \\
\hline Guamo & 28.01 & 39.19 & 33.94 \\
\hline Herveo & 11.22 & 27.42 & 23.43 \\
\hline Honda & 17.82 & 39.57 & 18.58 \\
\hline Icononzo & 20.43 & 41.62 & 34.76 \\
\hline Lérida & 25.89 & 32.24 & 27.35 \\
\hline Líbano & 20.87 & 44.28 & 29.83 \\
\hline Mariquita & 16.97 & 39.89 & 23.50 \\
\hline Melgar & 14.13 & 27.28 & 16.54 \\
\hline Murillo & 33.59 & 42.38 & 39.61 \\
\hline Natagaima & 41.33 & 58.47 & 47.07 \\
\hline Ortega & 43.62 & 70.61 & 63.97 \\
\hline Palocabildo & 30.65 & 40.86 & 38.00 \\
\hline Piedras & 26.21 & 36.62 & 33.51 \\
\hline Planadas & 36.77 & 69.36 & 60.23 \\
\hline Prado & 18.84 & 54.49 & 40.27 \\
\hline Purificación & 26.01 & 43.35 & 33.58 \\
\hline Rioblanco & 33.42 & 72.57 & 65.96 \\
\hline Roncesvalles & 26.87 & 38.84 & 35.51 \\
\hline Rovira & 31.58 & 57.37 & 45.72 \\
\hline Saldaña & 27.85 & 36.00 & 31.47 \\
\hline San Antonio & 33.81 & 58.48 & 51.31 \\
\hline San Luis & 36.91 & 52.07 & 47.95 \\
\hline Santa Isabel & 27.99 & 29.67 & 29.09 \\
\hline Suárez & 38.13 & 62.58 & 52.00 \\
\hline Valle de San Juan & 37.31 & 56.55 & 48.74 \\
\hline Venadillo & 31.08 & 42.63 & 34.42 \\
\hline Villahermosa & 17.62 & 33.03 & 28.31 \\
\hline Villarrica & 25.22 & 41.61 & 35.44 \\
\hline TOTAL & 19.63 & 50.84 & 29.79 \\
\hline
\end{tabular}

En municipios del norte como Alvarado, Venadillo, Anzoátegui, Santa Isabel, Casablanca, Falan, Palocabildo y Lérida, la tasa de NBI oscila entre 40 y $55 \%$.

En el oriente del departamento las tasas de NBI más altas se sitúan en los municipios de Cunday, Villarrica, Dolores, Prado y Alpujarra, oscilando entre 40 y $50 \%$.

\section{A N N}




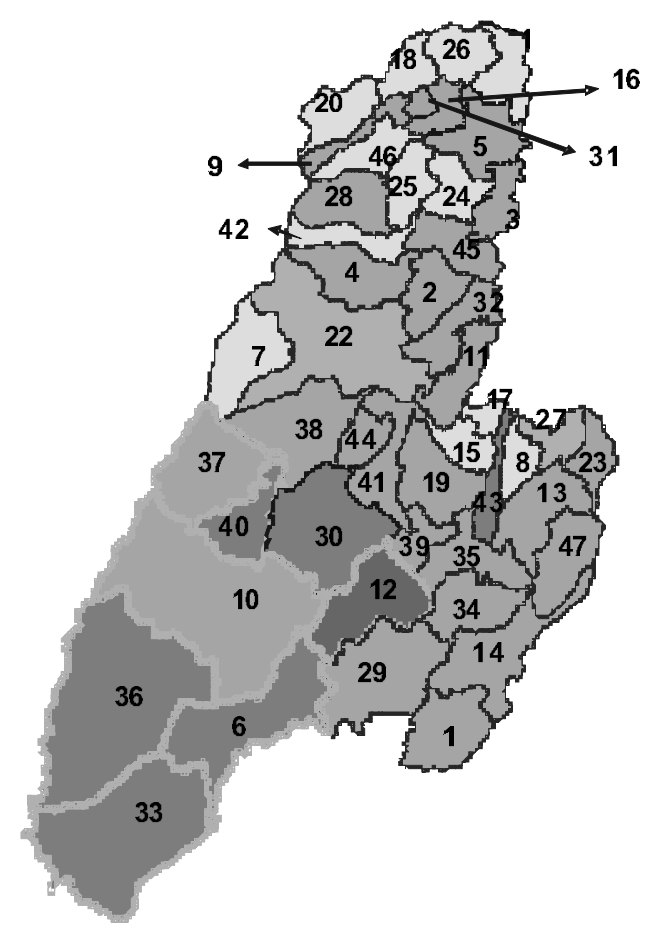

MUNICIPIOS

$\begin{array}{ll}\text { 1. } & \text { A pujarra } \\ \text { 2. } & \text { A varado } \\ \text { 3. } & \text { Ambalema } \\ \text { 4. } & \text { Anzo ategui } \\ \text { 5. } & \text { Armero Armero } \\ \text { 6. } & \text { Ataco } \\ \text { 7. } & \text { Cajamarca } \\ \text { 8. } & \text { Carmen Apicalá } \\ \text { 9. } & \text { Casabianca } \\ \text { 10. } & \text { Chaparra I } \\ \text { 11. } & \text { Coello } \\ \text { 12. } & \text { Coyaima } \\ \text { 13. } & \text { Cunday } \\ \text { 14. } & \text { Dolores } \\ \text { 15. } & \text { Espinal } \\ \text { 16. } & \text { Fál an }\end{array}$

$$
\begin{array}{ll}
\text { 17. Fándes } & \text { 33. Panadas } \\
\text { 18. Fresno } & \text { 34. Pado } \\
\text { 19. Guamo } & \text { 35. Purificaciòn } \\
\text { 20. He rveo } & \text { 36. Rioblan } \infty \\
\text { 21. Ho nda } & \text { 37. Roncesvalles } \\
\text { 22. Ibagué } & \text { 38. Rovira } \\
\text { 23. Icononzo } & \text { 39. Sal daña } \\
\text { 24. Lèrida } & \text { 40. San Anto nio } \\
\text { 25. Libano } & \text { 41. San Luis } \\
\text { 26. Mariquita } & \text { 42. Santa Isabel } \\
\text { 27. Melgar } & \text { 43. Suárez } \\
\text { 28. Murillo } & \text { 44. Valle San Juan } \\
\text { 29. Natagaima } & \text { 45. Ven adillo } \\
\text { 30. Ortega } & \text { 46. Vil lahermosa } \\
\text { 31. Palocabildo } & \text { 47. Vil larrica } \\
\text { 32. Piedras } &
\end{array}
$$

MUNIC IPIOS SEGÚN NBI

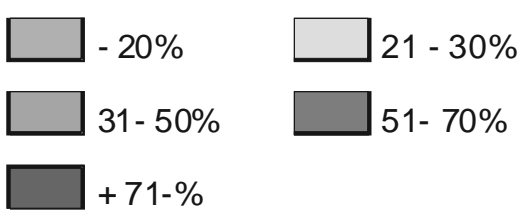

28 Municipios Ecorregión

FUENTE: Autor con base en DANE 2005.

Pero es evidente una relación entre las condiciones de pobreza de estos dos conjuntos de municipios y la presencia de impactos generados por el conflicto interno armado. Así se observa que los municipios con mayor desplazamiento forzado son en su orden Rioblanco, Ataco, Chaparral, Planadas, San Antonio, Rovira, Natagaima, Coyaima, Prado. Coinciden allí también, aunque se hace necesario un estudio más detallado de su relación, los actos delictivos relacionados con homicidio. Estas tasas, tomadas en la relación número de homicidios por cien mil habitantes, se concentran en la capital del departamento, sur ynoroccidente, comolo muestra el mapa siguiente.

En los municipios indicados se concentran también las peores condiciones de la red vial secundaria y terciaria y en la actualidad las distancias entre estos territorios y sus cabeceras urbanas y entre éstas y la capital departamental son similares a las de hace 20 años. (Ver mapa 2)

Asi por ejemplo, el recorrido entre Ibagué y Planadas se hace hoy en un tiempo que oscila entre 8 y 11 horas; entre Ibagué y Rioblanco, entre 5 y 6 horas; entre Ibagué y Roncesvalles entre 5 y 7 horas; entre Ibagué y San Antonio entre 4 y 6 horas; entre Ibagué y Villahermosa entre 4 y 5 horas; similar tiempo entre Ibagué y Casablanca, Ibagué y Santa Isabel, entre Ibagué y Alpujarra.

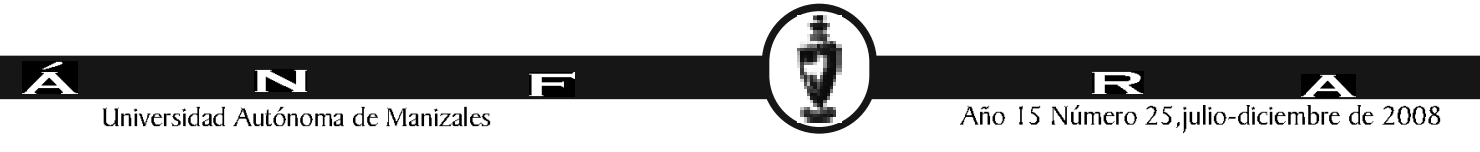


TOLIMA SEGÚN TASAS DE HOMICIDIOS POR 100.000 HABITANTES 2007

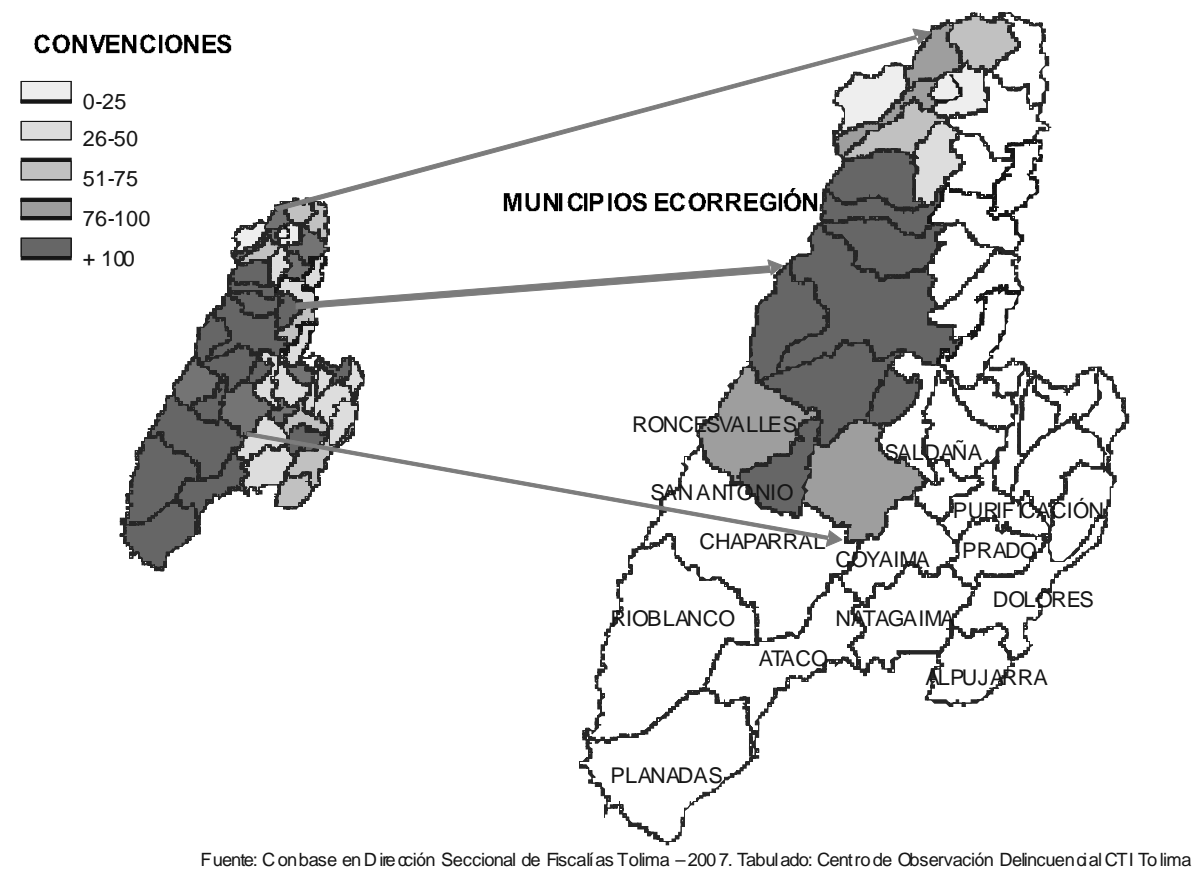

En ninguno de los casos la distancia es superior a los 170 kilómetros. Por ejemplo, cuando alguna vez la vía Chaparral-San Antonio tuvo una capa asfáltica, el recorrido entre este último municipio e I bagué podía hacerse en 3 horas y media, casi la mitad del tiempo que actualmente se requiere.

En municipios como Ortega, Coyaima y Natagaima, existen numerosas comunidades campesinas e indígenas que durante los periodos lluviosos se mantienen aisladas del resto del municipio por la carencia de puentes peatonales y vehiculares, cuyos costos exceden la capacidad del presupuesto municipal

Pese a lo que se siga en contrario, en municipios como Rioblanco, Ortega y Coyaima, existen escuelas cerradas desde hace más de tres años y se alega que hay docentes subutilizados. La infraestructura educativa está en estado deplorable y durante años no se ha efectuado inversión en ella, en todos los Municipios marginados del departamento, al sur, norte y oriente.

\section{Pobreza}

De acuerdo a los estudios realizados por el Departamento Nacional de Planeación sobre la Misión para el Diseño de una Estrategia para la Reducción de la Pobreza y la desigualdad- MERPD. La pobreza en el Departamento del Tolima es preocupante debido a que más del $54 \%$ del total de la población vive en condiciones de pobreza representada en 748 mil personas, donde las tasas de pobreza en promedio a partir del año 2002 hasta el 2005 están por encima del 60\%, 7 puntos por encima del nivel 
nacional y 10 puntos superiores a los departamentos de: Cundinamarca, Santander, Atlántico, Risaralda Quindío y Meta la pobreza oscila entre 40\% y 50\%.

Con relación a la indigencia 258 mil personas viven bajo estas condiciones, donde se presentan tasas del $23 \%$ en promedio a partir del periodo de análisis, 5 puntos por encima del promedio nacional, y 13 puntos superiores a los departamentos de: Cundinamarca, Santander, Atlántico, Risaralda, que oscilan entre el 10 y el 15\%. La intensidad de la pobreza y la indigencia está directamente relacionada con el nivel de ingresos por cada hogar para suplir sus necesidades primarias: alimentación, vivienda, servicios públicos, educación, salud, con varias limitantes en las posibilidades de consecución de trabajo por sus bajos niveles de educación lo cual no cumplen el perfil adecuado.

Al tercer trimestre del año 2005, la MERPD considera que el ingreso en las cabeceras, por persona era de $\$ 97.440 /$ mes lo que ( significa un costo medio de $\$ 1.083$, para cada una de las tres comidas del día) y, por hogar de 3,9 personas, era de $\$ 379.325 / \mathrm{mes}$. En las zonas rurales y por hogar de 4,2 personas, el valor de las líneas era más bajo: $\$ 303.432$ (indigencia) al mes. Otro de los indicadores que mide la pobreza en el Departamento del Tolima es el de Necesidades Básicas Insatisfechas a través de ella se identifican los hogares con algunos atributos que muestran carencias estructurales: Hogares en viviendas inadecuadas y viviendas sin servicios básicos, hogares con hacinamiento critico, hogares con alta dependencia económica y hogares con ausentismo escolar.

\section{Grupos Étnicos Históricamente Invisibilizados y Vulnerados.}

La memoria del "tolimense" es tan recortada como la ideología que lo creó. Ello obedece a que este "tolimense" no es otro que el heredero de la hacienda colonial española en cuya cuna se acuñó el extrañamiento de cualquier otro grupo humano.

Ello explica entonces por qué no aparecen en este tolimense hechos de reconocimiento de la presencia previa de los pueblos indígenas y afrodescendientes, muy anteriores a su conformación como étnia mayoritaria, construida sobre la base del exterminio de los primeros por los españoles.

Al respecto es necesario anotar que los pueblos primeros fueron los indígenas y que después de ellos fueron los africanos traídos como esclavos para trabajar en las minas. El pueblo mestizo es cronológicamente posterior.

Los indígenas fueron "resguardados" en el sur, como mecanismo efectivo de reducirlos territorialmente y al mismo tiempo justificar legalmente la posterior negación de sus derechos de reproducción social y étnica.

Con respecto a la población afrodescendiente, su presencia ha sido negada en la historia oficial del Tolima y aún hoy no se les reconoce como partícipes en la construcción histórica del territorio.

Uno y otro pueblo, incluidos los paeces, llegados al Tolima a partir de 1902, en plena Guerra de los Mil Días y más recientemente los Embera Chami', han permanecido invisibilizados por la sociedad mestiza mayoritaria, con lo cual resulta apenas obvio que el reconocimiento de sus derechos constitucionales y por acuerdos internacionales es marginal.
10 Una comunidad de esta étnia, c o n f o r m a d a p o r aproximadamente 100 personas desplazadas desde Chigorodó, Antoquia,se ha venido estableciendo en este municipio desde 1996.

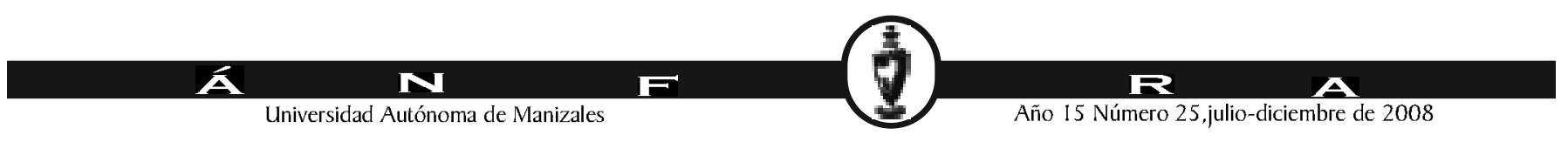


El gobierno departamental promulgó para atender a estas poblaciones las Ordenanzas 0051 de 2005, relacionada con la población indígena, y la Ordenanza 029 de 2006, relacionada con la población afrodescendiente, a las cuales debe dar cumplimiento.

\section{Dinámicas Incoherentes De Integración Regional}

Durante las últimas dos décadas el departamento ha estado próximo a diferentes procesos de promoción de alianzas regionales que buscan potenciar la capacidad y competitividad de la entidad territorial en el marco del contexto nacional.

Al mismo tiempo, la constitución de alianzas regionales constituye un espacio de renegociación de las relaciones entre el gobierno nacional y el bloque regional, con lo que se esperan obtener beneficios para cada uno de los departamentos vinculados.

La privilegiada localización del departamento contrasta con su ineficiente papel en procesos de integración regional y evidencia una lamentable incapacidad de comprender la flexibilidad que requiere al momento de asumir compromisos serios con sus vecinos de Cundinamarca, Caldas, Risaralda, Quindío, Valle del Cauca y Huila. Con cada uno de estos departamentos el Tolima comparte intereses comunes que están centrados en ecosistemas estratégicos, presencia de áreas deprimidas, presencia de conflicto interno armado y macroproyectos de desarrollo económico.

Una adecuada comprensión del carácter flexible de la conformación territorial, soportada en la condición de "bisagra" del departamento en el centro geográfico del país, resultará clave a la hora de decidirse por una POLÍTICA ESTRATÉGICA en materia de ordenamiento territorial y configuración regional.

Básicamente necesitamos definir una posición clara con relación a cuatro procesos diferenciados pero complementarios de regionalización para fines de desarrollo:

El primero con respecto a la propuesta de REGIÓN CENTRAL, en la que participan Bogotá, Cundinamarca, Boyacá y Meta, proceso que lleva ya varios años de trabajo y en el cual se han logrado avances políticos evidentes, reflejados en el macroproyecto Doble Calzada Bogotá-Buenaventura, que incluye el túnel de la Línea y la construcción de variantes en puntos críticos como Fusagasuga y Melgar, la reactivación del ferrocarril y la navegabilidad por el río Magdalena, así como propuestas claves como el aeropuerto alterno de carga de Flandes y la Central Nacional de Carga de Buenos Aires. El segundo está relacionado con la propuesta de la Ecorregión del Eje Cafetero, centrada en el desarrollo de procesos complementarios agroindustriales, industriales, manejo de ecosistemas estratégicos como el Parque Natural Nacional de los Nevados y túnel de la Línea.

El tercer proceso, abandonado por la elite política del Tolima, está relacionado con alternativas de región Alto Magdalena, conformada por los departamentos del Tolima y Huila.

El cuarto proceso es la Región Surcolombiana, en la cual entrarían los Departamentos del Tolima Huila, Caquetá, Putumayo, Cauca, Valle del Cauca y Nariño.

Al norte se ha promovido de tiempo en tiempo la propuesta regional "Corazón de Colombia", que se extiende por el Ilamado Magdalena Medio y que incluye a municipios de los departamentos del Tolima, Cundinamarca, Caldas, Boyacá y Antioquia.

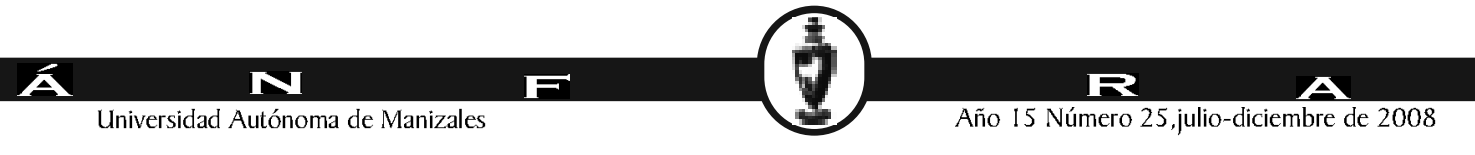


En todos los casos las propuestas de regionalización han sido más o menos documentadas y han alcanzado en diferentes momentos algún grado de protagonismo, sin llegar a convertirse en una preocupación política de los Estados en sus niveles territoriales departamentales.

\section{Baja inserción del departamento en el contexto internacional}

\section{Comercio Exterior del Tolima ${ }^{11}$}

Respecto al comercio exterior "la participación del departamento en el comercio exterior del país es mínima, pues apenas alcanza el $0.04 \%$ de las ventas externas totales. Y entre las exportaciones no tradicionales representa el $0.2 \%$, ubicándose en el lugar número 17 entre los departamentos". "El Tolima registró en 2005 una balanza comercial positiva de US $\$ 142,2$ millones, con exportaciones por US $\$ 161,1$ millones e importaciones de US $\$ 18,9$ millones. Pero estas exportaciones están dominadas por café $(83,5 \%)$ y a las exportaciones no tradicionales apenas representan el $16,5 \%$."

Cifras de la cooperación internacional para el Tolima

Colombia recibe actualmente de la cooperación oficial para el desarrollo, recursos por un monto de US $\$ 625.435 .017^{12}$, correspondiente a la ejecución de 491 proyectos. Del

Exportaciones Del Tolima Por Actividad Económica 2005

\begin{tabular}{|r|l|r|r|}
\hline № & \multicolumn{1}{|c|}{ ACTIVIDAD ECONÓMICA } & \multicolumn{1}{c|}{2005} & Participación \\
\hline 1 & Elaboración de otros derivados del café & $4,0334 \mathrm{E}+10$ & 47,5 \\
\hline 2 & Fabricación de tejidos y artículos de punto y ganchillo & $1,8768 \mathrm{E}+10$ & 22,11 \\
\hline 3 & Fabricación de prendas de vestir excepto prendas de piel & 8561764000 & 10,1 \\
\hline 4 & Comercio al por mayor de desperdicios o desechos industriales & 7607993000 & 8,9 \\
\hline 5 & Industrias básicas de metales preciosos & 1622095000 & 2,4 \\
\hline 6 & Cría especializada de aves de corral & 1587070000 & 1,9 \\
\hline 7 & Comercio al por menor de productos nuevos de consumo domestico ncp & 1332279000 & 1,8 \\
\hline 8 & Comercio al por mayor de prendas de vestir, accesorios de prendas de vestir & 1123788000 & 1,5 \\
\hline 9 & Comercio al por mayor de flores y plantas ornamentales & 760230000 & 1,3 \\
\hline 10 & Comercio al por menor de prendas de vestir y sus accesorios & $8,3809 \mathrm{E}+10$ & 0,8 \\
\hline & TOTALES & 98,7 \\
\hline
\end{tabular}

total nacional, el Tolima tiene en ejecución 19 proyectos de Cooperación, con un monto aproximado de US $\$ 5.136 .539^{13}$, frente a departamentos como Cauca con US $\$ 21.138 .897$ ( 40 proyectos), Antioquia US $\$ 45.032 .077$ (88 proyectos) y Nariño US \$ 28.264.653. ( 40 proyectos). El monto que recibe el Tolima representa el $0,82 \%$ de la cooperación oficial para el desarrollo que recibe Colombia.

Seguidamente se detalla la división de los 19 proyectos de acuerdo a los temas de cooperación:
11 POLITICA PÚBLICA Y A G E N D A PAR A L A INTERNACIONALIZACION DEL TOLIMA. Documento de Trabajo. Asesoría de Asuntos Internacionales. Mayo de 2007.

12 Agencia Presidencial para la Acción Social y la Cooperación Internacional. Mapa de Cooperación Internacional

13 Idem.

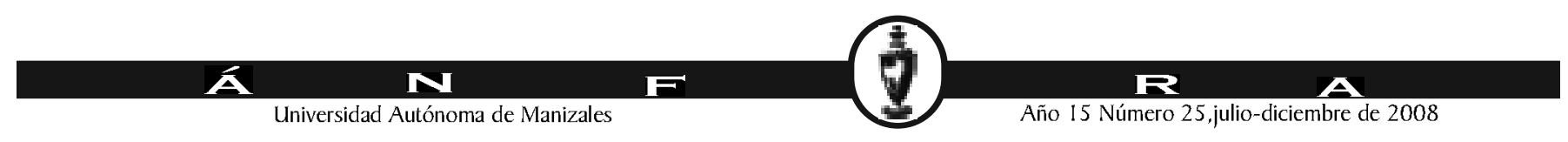




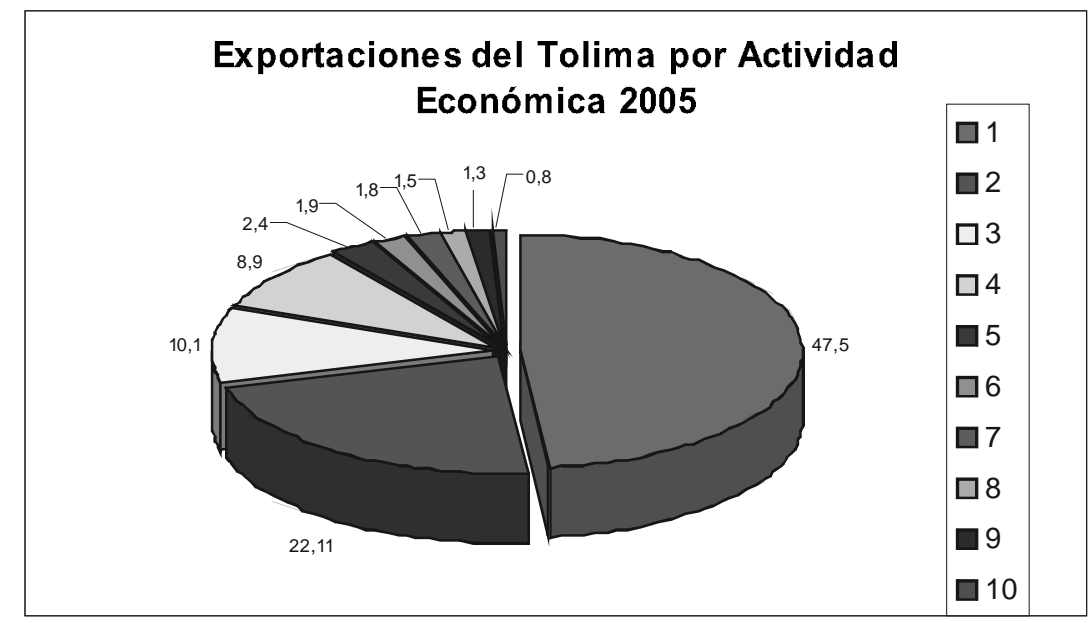

\begin{tabular}{|r|l|r|r|}
\hline № & Balanza Comercial & \multicolumn{1}{c|}{ Valor \$ } & \multicolumn{1}{c|}{ Valor US\$ } \\
\hline 1 & Exportaciones (Valor FOB) & $374,256,008$ & $161,150,957$ \\
\hline 2 & Importaciones (ValorCIF) & $\mathbf{7 4 , 3 3 5 , 8 2 2}$ & 20,423 \\
\hline 3 & Balanza Comercial & $326,920,186$ & $161,130,534$ \\
\hline
\end{tabular}

Es apenas a partir del año 2006 que el gobierno departamental adopta una posición con relación a la necesidad inaplazable de que el departamento construya una política pública de internacionalización, en cuya formulación vienen participando diversos actores claves de la economía, la academia, la cultura y sectores sociales.

\begin{tabular}{|l|c|r|}
\hline \multicolumn{1}{|c|}{ Tema } & \# de proyectos & \multicolumn{1}{c|}{ Monto } \\
\hline Agropecuario & 2 & US\$ 159.832 \\
\hline Derechos Humanos & 4 & US\$2.461.526 \\
\hline Desarrollo Alternativo & 2 & US\$371.900 \\
\hline Desarrollo Social & 6 & US\$ 1.790.881 \\
\hline Medio Ambiente & 2 & US\$228.807 \\
\hline Paz y Desarrollo Regional & 1 & US\$50.000 \\
\hline Sin Clasificar & 2 & US\$73.593 \\
\hline \multicolumn{2}{|c|}{ TOTAL } & US\$ 5.136.539 \\
\hline
\end{tabular}

Fuente: Acción Social

La política de internacionalización del Departamento solo puede concretarse en la medida en que se dispongan los mecanismos que le den sostenibilidad a la Agencia Regional para el Desarrollo, como instancia adscrita al Despacho del Gobernador o en una reestructurada Secretaría de Planeación.

\section{A $\quad \mathbf{N}$}


La Agencia deberá concebirse como un organismo promotor del Departamento ante los organismos nacionales e internacionales de cooperación para el desarrollo. Deberá además liderar procesos de capacitación de las entidades territoriales municipales, de las organizaciones sociales y ONG en aspectos relacionados con la cooperación nacional e internacional para el desarrollo.

La Agencia Regional para el Desarrollo ARD Tolima, deberá construir un espacio virtual que permita la generación de una red de consulta pública y de intercambio de información sobre relaciones internacionales, de manera oportuna.

\section{Ausencia de instancias de planificación del desarrollo territorial entre los niveles municipal y departamental.}

Con la entrada en vigor de políticas nacionales como las leyes 550 de 1999 y 617 de 2000, si bien se llamó la atención acerca de la crisis de las entidades territoriales departamentales y municipales, el departamento vio pasar una sombra sobre su funcionamiento, pues si antes de éstas no había logrado construir un escenario apropiado de coordinación y gerencia de las políticas territoriales de desarrollo en los niveles municipal y regional, ahora se veía en la condición impuesta de centrarse en la resolución de problemas fiscales de fondo y en los consecuentes procesos de reestructuración administrativa, abandonando prácticamente su función de coordinación de las labores de planificación del desarrollo territorial.

Los municipios quedaron entonces expuestos, no solo a su propia crisis que la mayoría no logra aún superar satisfactoriamente sino a una verdadera desconexión con respecto a unos lineamientos de la política departamental que no existen como política pública coherente y de carácter estratégico.

En este orden de cosas, se liquidaron activos de la entidad territorial, pero se liquidaron también funciones claves para el desarrollo territorial, como la coordinación que podrían desempeñar de manera eficiente las secretarías de despacho en estrecha coordinación con los gobiernos municipales. Se cita como ejemplo de esta situación lamentable, cómo mientras se liquidan las UMATA, los nuevos centros provinciales no son dotados de los recursos humanos, técnicos ni financieros para asumir de manera oportuna y eficiente ni la gestión ni la asistencia técnica en sus respectivas jurisdicciones; como a pesar de que se produjeron unos lineamientos para el ordenamiento territorial departamental nunca pudo realmente coordinarse un comité o instancia interinstitucional que garantizara un proceso aceptable de formulación y aplicación de los esquemas y planes de ordenamiento territorial; mientras se liquidaba la Secretaria de Obras Públicas, los problemas en la red vial secundaria y terciaria del departamento se multiplicaron; como pese a esfuerzos de administraciones anteriores por promover la asociatividad municipal el departamento retrocedió en procesos de planificación regional y provincial, afectando gravemente la unidad de la entidad territorial departamental, expuesta a campañas de desvertebramiento desde los vecinos departamentos del Huila y Caldas y carente de propuestas integrales de desarrollo.

En suma, el sueño de un solo Tolima se ha ido desdibujando y demanda un esfuerzo de gobierno que le apueste a retos estratégicos, contenidos en parte en la Visión Tolima 2025, pero aún no concretados en una Agenda Estratégica de Desarrollo, como se ha señalado en las tendencias internacionales que jalonan los procesos del desarrollo regional.

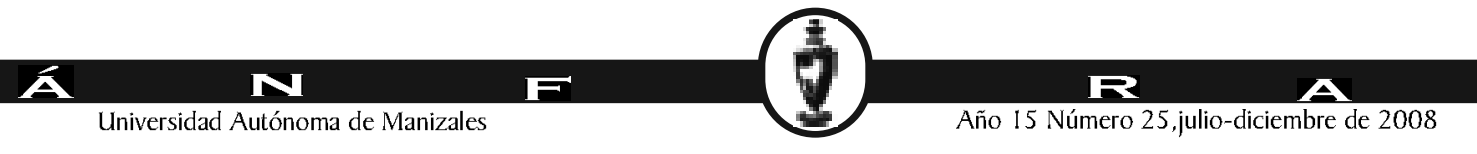


El Tolima sigue esperando una oportunidad con la suficiente fuerza de convocatoria para construir un departamento fuerte, solo posible a partir de municipios fuertes y de una política pública departamental coherente con los niveles y competencias de sus niveles municipal y departamental de desarrollo, pero fuertemente articulado a las dinámicas de integración y cooperación regional.

\section{Cultura política marcada por prácticas premodernas (Corrupción y Clientelismo).}

El Departamento del Tolima ha sido estigmatizado históricamente por la prevalencia de prácticas políticas contrarias a la ética del ejercicio de la función pública.

Profundas huellas han dejado episodios lamentables de un infortunado ejercicio de la política en el departamento y no menores han sido las que por cuenta de las rivalidades irracionales entre sectores políticos han desgastado energías que utilizadas a favor del desarrollo regional hubieran resultado fructíferas y permitirían ofrecer hoy un panorama diferente del Tolima.

Urge un Pacto Político inspirado en el sueño de un Tolima Posible en el que el interés colectivo prime sobre el interés particular y de grupos y en el que el Departamento sea el objetivo presente en el imaginario colectivo.

Las usuales frases y diatribas contra la corrupción y el clientelismo no pueden seguir siendo la consigna ni la frase de cajón cuando las prácticas puestas en escena por quienes las han coreado tantas veces muestran ser solo una estratagema para perpetuarlas y engañar al electorado.

Se reclaman demostraciones concretas que privilegien el debate democrático franco y abierto, de cara a la gente, y que contribuyan a la construcción de una nueva ciudadanía, una ciudadanía moderna que será la única en la cual aquellos flagelos premodernos no tendrán lugar y se abrirá paso una cultura política generadora de paz y convivencia.

A ello será necesario complementar con la transformación del estilo de gobierno, el cual deberá privilegiar la planificación de largo plazo y la continuidad de programas y proyectos que hayan mostrado impactos positivos sobre el mejoramiento de la calidad de vida de las comunidades y hayan contribuido al fortalecimiento de prácticas modernas de participación comunitaria y de relaciones entre las organizaciones sociales y el gobierno.

\section{El plan ante los retos de los ODM}

Por considerarlo de la mayor pertinencia, se trascribe como introducción al presente capítulo, la misma que fue suscrita por el gobernador del Tolima ${ }^{14}$ y que hace de preludio al Plan de Desarrollo del Departamento. Es también un gesto de respeto por la intencionalidad del propósito, que luego de diez meses de ejercicio de mandato, se ha mantenido fiel a lo aquí expresado.

Convoqué a los Tolimenses con un programa que planteaba soluciones para los problemas más sentidos por ellos: el desempleo, el acceso y la permanencia en la educación, contar con servicios de salud, proteger a la
14 Oscar Barreto Quiroga, en la presentación del Plan de Desarrollo "Soluciones para la gente 2008-2011"

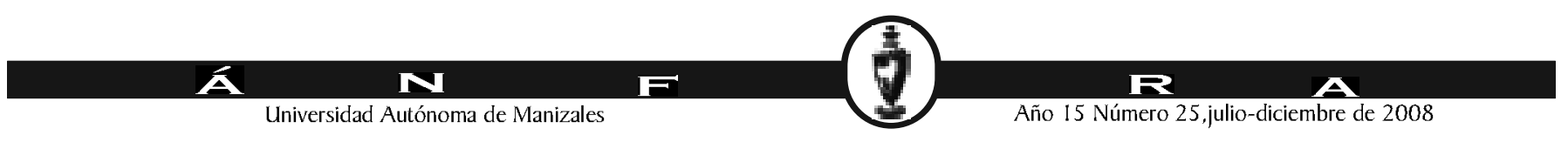


familia atendiendo a quienes dependen de ella porque no pueden valerse por sí mismos como las niñas y los niños, los jóvenes, los ancianos y aquellos que tienen alguna discapacidad $y$, un problema crucial que impide el progreso: las vías que nos unen y permiten la actividad económica y social.

El equipo de gobierno trabajó conscientemente en las propuestas y realizó un trabajo técnico y académico muy importante para elaborar el Plan, que puede ser consultado en sus múltiples volúmenes. Pero un Plan que busque solucionar los problemas de la gente debe ser entendido por sus destinatarios. Por tal motivo, y acorde con mi estilo de gobierno, este Plan está escrito y hecho para todos, para que siendo entendido pueda ser seguido, puedan pedirme cuentas, puedan proponerme mejoras y formas de hacer las cosas, para que la sabiduría de las gentes pueda interpretarlo y asumirlo como propio. Este es un Plan para la Gente.

Más que de la técnica este Plan nace de la consulta a los ciudadanos y especialmente a los ciudadanos de la Provincia Tolimense, a quienes busca beneficiar de manera preferencial. Durante estos cuatro meses de gobierno se han venido realizando encuentros con los ciudadanos en los Municipios, donde se ha socializando la propuesta del Plan y han sido consultados todos los actores sociales, así como los concejales, los discapacitados, los gremios económicos y la academia, buscando la participación e inclusión de todos en la construcción de las políticas públicas y de desarrollo del Departamento.

Pongo algunos ejemplos: los cinco municipios más pobres del Tolima están en el sur y son los más afectados por la violencia y el irrespeto a los derechos fundamentales, diez cabeceras municipales carecen de vía pavimentada, la mayor pobreza está en el campo, catorce de cada cien tolimenses son analfabetas y están casi todos en los municipios pequeños y en el campo. No puede ser un plan para la gente y para buscar soluciones para la gente sino es un plan que beneficie mayormente a la provincia.

Todos los planes se presentan por sectores y dicen separadamente que van a hacer en educación, en salud, en vías o en agricultura. Se pierde finalmente el sentido del Plan. Este Plan se presenta por propósitos, para que pueda ser comprendido como una propuesta para el bienestar de las gentes y pueda ser evaluado por lo que logra y no por lo que hace. Este gobierno será de resultados y no simplemente de enumerar lo mucho que hace aunque nada se logre.

Hemos escogido tres propósitos básicos que resumen los propósitos: inclusión social y competitividad y desarrollo sostenible. Paso a explicar lo que esas palabras significan. Por múltiples razones muchos ciudadanos no pueden acceder al trabajo, a la salud, a la educación, a la vivienda digna y casi siempre por dos razones: porque son pobres o porque viven en lugares alejados e incomunicados; a ellos que son excluidos de las posibilidades de una vida digna debemos ayudar para que se incluyan en los beneficios del desarrollo. Eso es inclusión social.

De otra parte los beneficios del progreso tampoco se reparten por igual. Unas regiones y naciones progresan y otros no. Una de las razones principales es

14 Oscar Barreto Quiroga, en la presentación del Plan de Desarrollo "Soluciones para la gente 2008-2011"

\section{A $\quad \mathbf{N}$ Universidad Autónoma de Manizales


porque los bienes que producen no pueden competir con los producidos en otras regiones o países, bien porque resultan más costosos en su producción o en su transporte, o no son de buena calidad o los producimos de manera desordenada y cada uno por aparte.

Buscar que esos bienes que producimos y los servicios que prestamos puedan competir en los mercados es buscar la competitividad. Así de sencillo aunque las palabras suenen raras. Hay una verdad que no puede ignorar el gobernante ni tampoco los ciudadanos: detrás de cada problema que parece sencillo hay un gran problema por resolver. Detrás del padre sin empleo hay un gran problema: la economía de la región es insuficiente para crear puestos de trabajo, como en el caso nuestro, o una carencia de posibilidades de educación que le brinde capacidades o competencias. Detrás de cada niño enfermo de diarrea hay un problema de falta de agua potable que debe ser solucionado. Detrás de cada producto agrícola que produce pérdidas a quienes lo cultivan por causa del verano, hay la necesidad de contar con riego. Para arreglar las vías debemos contar con dinero y eso implica solucionar la crisis financiera del departamento. Así que solucionar los problemas de la gente es a su vez solucionar los grandes problemas que los causan y que han hecho del Tolima un departamento rezagado.

Los Tolimenses encontraran en este Plan propuestas nuevas y atrevidas por las metas que se plantea. Las soluciones no deben plantearse por los recursos que se tengan disponibles sino por las necesidades y problemas que enfrentan. Programas y proyectos del tamaño de las necesidades y de los sueños que hagan necesaria la gestión, la búsqueda de recursos y de soluciones creativas. Muchas de ellas pensadas para que continúen en el tiempo como programas de muchos periodos de gobierno. Tal el caso de las propuestas para los jóvenes en educación y salud.

Pido a la Asamblea del Tolima y a mis conciudadanos que el análisis del Plan de Desarrollo se aleje de visiones partidistas, de odios y rencores. El gobierno que presido ha dado ejemplo de que eso es posible e igualmente la Asamblea del Tolima. Las gentes deben recuperar la fe en las instituciones, volver a creer en los gobernantes, unirse para lograr propósitos. Pido a todos que me ayuden en este cambio de valores.

\section{Visión de desarrollo del Tolima}

En el 2025 el Tolima será el punto de encuentro de las posibilidades de futuro de Colombia

Lo vislumbramos como un departamento que trabaja con ahínco por su consolidación en el desarrollo, en términos de la solidaridad, como actuación en conjunto, para satisfacer intereses en común, y de un ejercicio empresarial asertivo y prospectivo. Vemos un departamento a la vanguardia de los depositarios del conocimiento, de mediadores culturales y promotores del sentido de pertenencia de una nación rica en parajes, historia y asentamientos humanos, susceptibles de ser difundidos al mundo. Lo percibimos como el vértice agroindustrial con principios instalados en el desarrollo sostenible y centrado en las personas e instalado en su real dimensión entre lo rural y lo urbano. Estos principios habrán favorecido en crecimiento económico, para minimizar

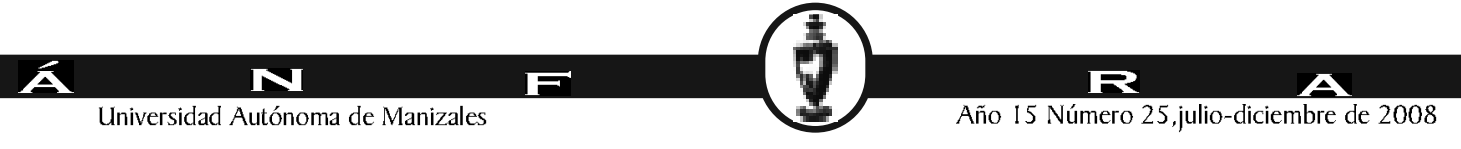


la pobreza material y de espíritu, y privilegiar la equidad, como resultado del ejercicio de una ciudadanía autónoma, solidaria y gestora de futuros posibles. Esta visión se funda en tres principios: un desarrollo centrado en las personas, sostenible y sustentable, y equilibrado ente lo rural y lo urbano; apunta a tres fines, crecimiento económico, la reducción de la pobreza y la equidad; busca consolidar entre los tolimenses la iniciativa empresarial, el ejercicio de la ciudadanía y la solidaridad; le da fuerza a la idea de ser el principal centro de logística del país, al turismo integral y al desarrollo de la agroindustria de valor agregado. Todo esto incorporado la Educación, la ciencia, la tecnología y la innovación como parte de la canasta social de los tolimenses. ${ }^{15}$

\section{Plan de desarrollo departamental Vs ODM}

El Plan de Desarrollo "Soluciones para la gente 2008-2011", derivado del Programa de Gobierno inscrito ante la Registraduría del Estado Civil por el electo gobernador del Tolima, expresa que en su formulación se han consultado todas las vertientes políticas y todos los sectores sociales del departamento, esforzándose el Equipo realizador por reflejar en él no solo una estructura que rompa los estilos convencionales del documento Plan sino por mostrar la coherencia entre los documentos finales, el programa de gobierno, los intereses del pueblo tolimense y las políticas nacionales de desarrollo.

Los ejes del Plan (Capitulo II) -Inclusión social y formación del capital Humano, Competitividad Regional, Ambiente Sostenible y Políticas Transversales- están precedidos de los propósitos de Inclusión social (Capítulo I) y competitividad, que descansan en el Soporte Institucional (Eje III).

Esta estructura, sencilla a la luz de la tradición de ejercicios de formulación de planes de desarrollo, expresa la intencionalidad incluyente del Plan y deja claro que la acción de gobierno, una vez concluido el debate electoral y la elección del nuevo mandatario, da paso a un nuevo escenario de concertación de propósitos colectivos, cuya más clara manifestación empezó a verse con el acto conjunto de posesión del gobernador y el alcalde de la capital departamental, en el cual además de la madurez política manifestada en sus intervenciones, asumieron el compromiso de formular la Agenda Ibagué-Tolima ${ }^{16}$, como una respuesta al tradicional descuido de la entidad departamental a los problemas de la ciudad capital.

Debe tenerse en cuenta que la gobernación fue ganada por una coalición de diferentes sectores, encabezada por el conservatismo, que enfrentaban al candidato oficial del liberalismo, mientras la alcaldía de Ibagué fue ganada por el candidato oficial del liberalismo. Hay aquí ya un ejemplo aleccionador de buena práctica política, digno de ser reconocido.

Al definir la estructura del Plan, el eje I, Capítulo I, Propósitos del Plan, Objetivos de Desarrollo, expresa:

\section{Las metas del Milenio}

El Programa de Gobierno declara que acoge los Objetivos del Milenio que la nación ha hecho suyos y el Plan Nacional de Desarrollo que orienta al país hasta el año 2.010. Así busca además construir sinergias entre los distintos niveles de gobierno y enmarcar al Tolima en el contexto Colombiano y en el ámbito de las preocupaciones de la Comunidad Internacional, a los cuales recurrirá para hacer realidad sus propósitos y metas2.
15 La formulación de las Agendas fue realizada en el marco del Convenio PNUD - Corporación Desarrollo y Paz del Tolima TOLIPAZ, adelantado entre julio y diciembre de 2005 por el Geógrafo Miguel Antonio Espinosa Rico, Consultor del proyecto suscrito

16 Simultáneamente con la formulación del Plan de Desarrollo Departamental, se formuló la Agenda Ibagué Tolima, que constituye un compromiso de acciones conjuntas con recursos del Municipio y del Departamento. Entre diversas acciones, el Departamento suscribió un Convenio con la Fundación Social para adelantar un proceso centrado en el Modelo de Desarrollo Integral Local DIL, que esta entidad ha estructurado en su trabajo en diferentes ciudades colombianas y que involucra en Ibagué a las comunas 6, 7 y 8.

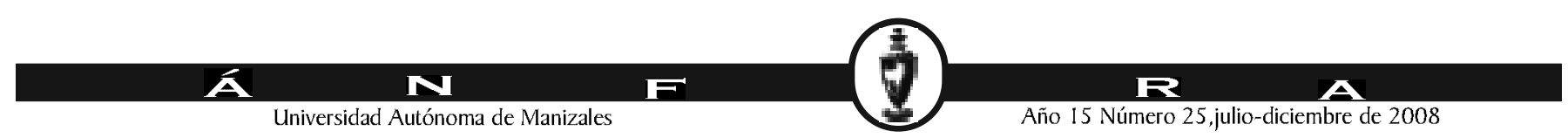


El gobierno nacional vertió en el CONPES 91 de 14 de marzo de 2005 denominado “METAS Y ESTRATEGIAS DE COLOMBIA PARA EL LOGRO DE LOS OBJETIVOS DE DESARROLLO DEL MILENIO - 2015", las orientaciones y acciones necesarias para lograr su cumplimiento y destaca que en el nivel de la nación resulta posible alcanzarlas pero que muchos territorios muestran un particular atraso en los indicadores de las metas haciendo que el punto de partida diste mucho de ellas y que por tanto se requiere esfuerzos municipales y departamentales diferenciales.

El pobre demanda mayores servicios del Estado y su condición de marginalidad lo convierte en un demandante consuetudinario de subsidios y ayudas del mismo, es por ello que el combate a la pobreza debe ser ante todo un postulado democrático, garantizar a partir de la salud y la nutrición, igualdad de oportunidades y del otro una estrategia económica conducente a convertir a los pobres en agentes productivos autónomos.

El Plan de Desarrollo garantizará que el Departamento del Tolima cumpla los Objetivos del Milenio, trazados por Naciones Unidas, particularmente en cuanto hace a madres gestantes y lactantes y niños menores de cinco años y escolarizados.

Una síntesis de la incorporación de los ODM en el Plan de Desarrollo del Tolima es la que sigue.

Plan de Desarrollo “Soluciones para la gente 2008-2011" y Objetivos de Desarrollo del Milenio

\begin{tabular}{|c|c|c|c|}
\hline OBJETIVO & INDICADOR & LÍNEA DE BASE & $\begin{array}{c}\text { META } \\
\text { CUATRIENIO }\end{array}$ \\
\hline \multirow{5}{*}{$\begin{array}{l}\text { 1. ERRADICAR LA } \\
\text { POBREZA EXTREMAY } \\
\text { EL HAMBRE }\end{array}$} & Índice de condiciones de vida & 73.05 & 76 \\
\hline & Incidencia de la pobreza o porcentaje de pobres & 56.85 & 55.85 \\
\hline & Tasa de desempleo & 13.9 & 8.9 \\
\hline & Índice de desplazamiento & 8.67 & N.D. \\
\hline & $\begin{array}{l}\text { Tasa de desnutrición global: Porcentaje de niños menores de } 5 \\
\text { años con peso menor al normal }\end{array}$ & 9 & 7 \\
\hline \multirow{9}{*}{$\begin{array}{l}\text { 2. LOGRAR LA } \\
\text { ENSEÑANZA } \\
\text { UNIVERSAL }\end{array}$} & Tasa de analfabetismo $(15-24)$ & 13.6 & 8.4 \\
\hline & Tasa de cobertura escolar neta en básica primaria $(6-10)$ & 91.36 & 95 \\
\hline & Tasa de cobertura escolar neta en básica secundaria (11-14) & 59.56 & 65.5 \\
\hline & Tasa de cobertura escolar neta en media $(15-16)$ & 29.33 & 35 \\
\hline & $\begin{array}{l}\text { Tasa de cobertura escolar bruta en básica (6 } \\
\text { secundaria }\end{array}$ & 113 & 120 \\
\hline & Tasa de cobertura escolar bruta en media $(16-17)$ prima & 60.05 & 80 \\
\hline & Tasa de deserción preescolar & 11.48 & 8.3 \\
\hline & Tasa de deserción básica primaria & 11.01 & 8.3 \\
\hline & Tasa de deserción básica secundaria y media & 9 & 8.3 \\
\hline
\end{tabular}

\section{太}




\begin{tabular}{|c|c|c|c|}
\hline \multirow{6}{*}{$\begin{array}{l}\text { 5. MEJORAR LA SALUD } \\
\text { MATERNA }\end{array}$} & Razón de mortalidad materna (registrada) & $55.99 \times 100.000$ & $52 \times 100.000$ \\
\hline & Porcentaje de atención institucional de parto & 70 & 92 \\
\hline & Porcentaje de atención del parto por personal calificado & 95 & 97 \\
\hline & $\begin{array}{l}\text { Porcentaje de mujeres de } 15 \text { a } 19 \text { años que han sido madres o se } \\
\text { encuentran embarazadas }\end{array}$ & 17 & 15 \\
\hline & Tasa ajustada de mortalidad por cáncer de cuello uterino & $13 \times 100.000$ & $11 \times 100.000$ \\
\hline & Porcentaje de gestantes con 0 controles prenatales & 3.82 & 1.9 \\
\hline \multirow{4}{*}{$\begin{array}{l}\text { 6. COMBATIR EL } \\
\text { VIH/SIDA, EL PALUDISMO } \\
\text { Y OTRAS ENFERMEDADES }\end{array}$} & Prevalencia de infección por VIH/SIDA & 0.33 & 1.22 \\
\hline & Mortalidad anual por SIDA & 66 casos & $\begin{array}{l}\text { Por debajo de } 66 \\
\text { casos }\end{array}$ \\
\hline & Incidencia de infección vertical por SIDA & ND & ND \\
\hline & Razón de mortalidad por dengue & 0 & 0 \\
\hline \multirow{5}{*}{$\begin{array}{l}\text { 7. GARANTIZAR LA } \\
\text { SOSTENIBILIDAD DEL } \\
\text { MEDIO AMBIENTE }\end{array}$} & Cobertura bosques o reservas naturales protegidas en el Departamento & 11.223 .547 has. & 11.223 .547 has. \\
\hline & $\begin{array}{l}\text { Porcentaje hogares con acceso a agua mediante conexión a sistemas de } \\
\text { acueducto (urbano y rural) }\end{array}$ & 81.46 & 85 \\
\hline & $\begin{array}{l}\text { Porcentaje hogares con desagüe mediante conexión a sistemas de } \\
\text { alcantarillado (Urbano y rural - DANE Redatam) }\end{array}$ & 70.41 & 75 \\
\hline & Déficit cualitativo de vivienda & 11 & 9.6 \\
\hline & Déficit cuantitativo de vivienda & 24.201 & 19.201 \\
\hline \multirow{4}{*}{$\begin{array}{l}\text { 8. FOMENTAR UNA } \\
\text { ASOCIACIÓN MUNDIAL } \\
\text { PARA EL DESARROLLO }\end{array}$} & Indicador de desempeño fiscal (2006) & 58.69 & 65 \\
\hline & Índice de transparencia Departamental I & 76 & 100 \\
\hline & Cobertura conectividad a Internet & 53.48 & 70 \\
\hline & Cobertura de telefonía celular o fija & 41.4 & ND \\
\hline
\end{tabular}


De la mano con los niños, niñas y adolescentes a la Escuela. Los progresos realizados hacia la ampliación del acceso han sido lentos, y los niños, niñas, adolescentes y jóvenes más pobres son los que corren el riesgo de ser excluidos del sistema. Un programa de inclusión y equidad para este sector de la población exige el desarrollo de tres acciones concretas: 1. Ampliación de la oportunidades de acceso a la educación, 2. Desarrollo de estrategias para garantizar la permanencia y continuidad y 3 . El restablecimiento del derecho, en los momentos en que el sistema ha excluido a los niños, niñas, adolescentes y jóvenes.

\begin{tabular}{|c|c|}
\hline Componente & Meta del cuatrienio \\
\hline Niños y niñas de 3 y 4 anos atendidos a través del bancos de oferentes & 14.678 \\
\hline Nuevos cupos escolares en grado obligatonio (5 anos) & 3.083 \\
\hline $\begin{array}{l}\text { Ninos y niñas de atto riesgo de deserción atendidos por el sistema escolar (Educación } \\
\text { básica) }\end{array}$ & 4.000 \\
\hline Madres comuntarias del KCBF asesoradas en procesos pedagdoicos. & 1577 \\
\hline $\begin{array}{l}\text { Hogares del ICBF que atienden población de } 3 \text { y } 4 \text { anios intervenidos con material } \\
\text { educativo. }\end{array}$ & 1.431 \\
\hline
\end{tabular}

\section{Escuela que garantiza y reestablece derechos ${ }^{18}$}

En el año 2007, 226.555 niños, niñas, adolescentes y adultos asistieron, a las instituciones y centros educativos a cursar los niveles de preescolar, básica primaria, básica secundaria y media ${ }^{19}, 12.099$ más que los matriculado en el año 2006. En este periodo la cobertura bruta llego al $98,19 \%$, mientras que la cobertura neta solo alcanzó el $62,26 \%$, en promedio para todos los niveles.

\section{Gráfica 6. Cobertura bruta y Neta por Nivel Educativo. 2007}

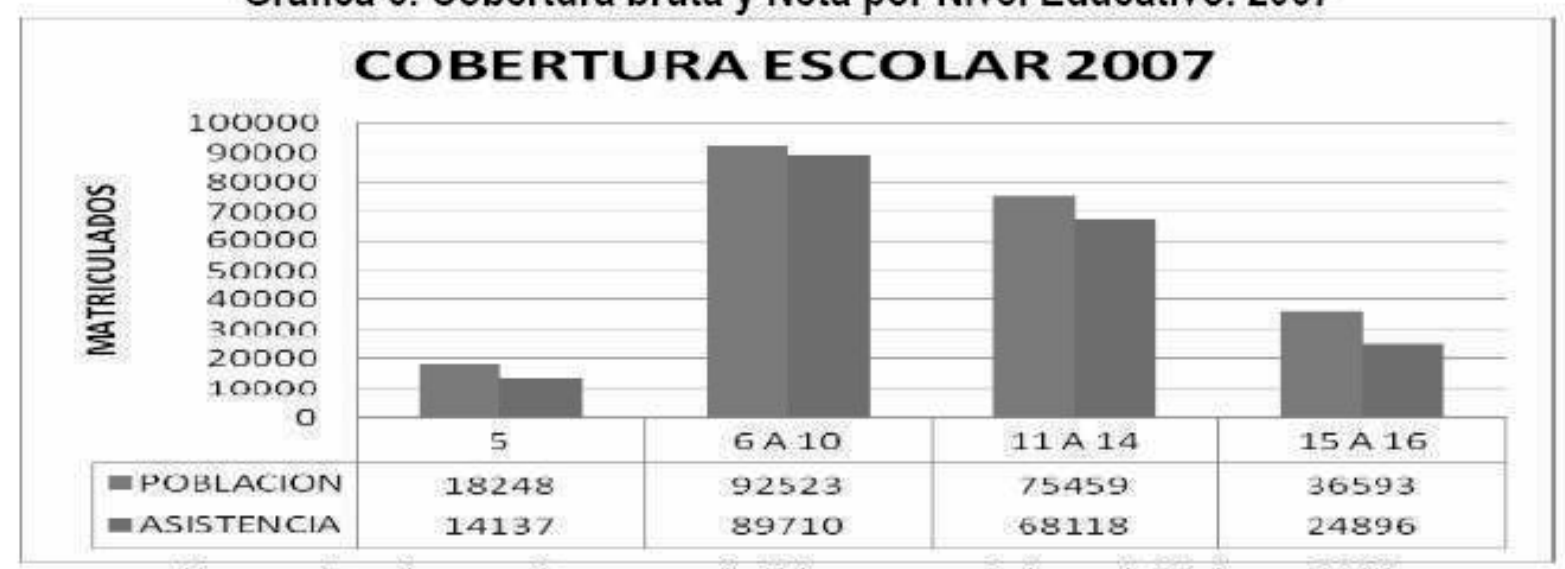

Fuente: Estadisticas Secretaria de Educación y Cultura del Tolima - 2007 
Según las proyecciones de población calculadas por el DANE, para el año 2007 el número de niños, niñas y jóvenes entre los 5 y 16 años de edad, en los 46 municipios no certificados es de 222.823 de los cuales el $88,34 \%$ asistió a las instituciones y centros educativos. Esta cifra indica que 25.962 niños, niñas y jóvenes no recibieron educación y quedaron excluidos del sistema escolar.

La deserción y la reprobación escolar son dos temas que deben convertirse en oportunidades de mejoramiento, en el cuatrienio. Las estadísticas finales del año 2006 indican que la mortalidad educativa llegó al $15,2 \%$ de los cuales el $67,41 \%$ es atribuido a la deserción escolar y el 32,59\% a la reprobación. Los grados escolares con mayor deserción son el 10, 20, y 60, donde de cada 100 niños y niñas que ingresan al sistema, 15,11 y 12 respectivamente, dejan las aulas antes de concluir el año escolar. En el Tolima, según datos registrados en el Censo de población de 2005, la tasa promedio de analfabetismo en la franja de población de 5 años, y más en la cabecera, es de 13,14\% y en resto de $19,09 \%$. Estas cifras muestran un promedio de analfabetismo del $13,6 \%$ en los 46 municipios no certificados en educación.

Los mejores resultados se presentan en los municipios de Espinal y Melgar. En estas localidades los índices de analfabetismo están por debajo del $10 \%$.

\section{Grafica 8. Población iletrada por municipios según Censo 2005.}

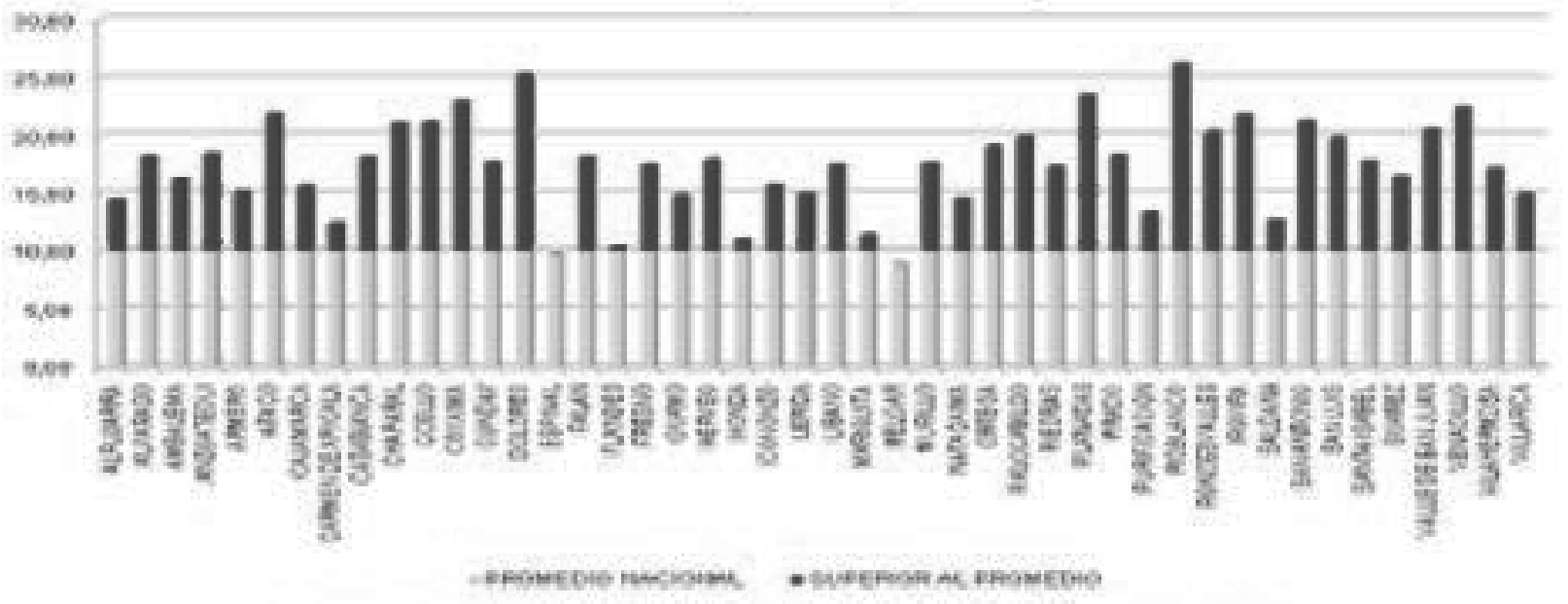

Fuente: Eatadisticas Secretaria de Educaclón y Cultura del Tollma - 2006

En otro escenario, a pesar de no existir una información confiable que determine con exactitud las coberturas reales de atención en la población especial, las cifras indican una atención escolar a 2.380 niños y niñas con necesidades educativas especiales, 1.820 menores trabajadores, 2.805 desplazados, 12.500 jóvenes y adultos iletrados, 292 desmovilizados del conflicto armado, 66 adolescentes en conflicto con la ley y 10.693 indígenas.

La propuesta de recuperar la educación, busca fortalecer las escuelas públicas y mejorar su ambiente para que desarrolle procesos pedagógicos de calidad, superando la creencia de que la escuela pública es para los "niños pobres". En este sentido la

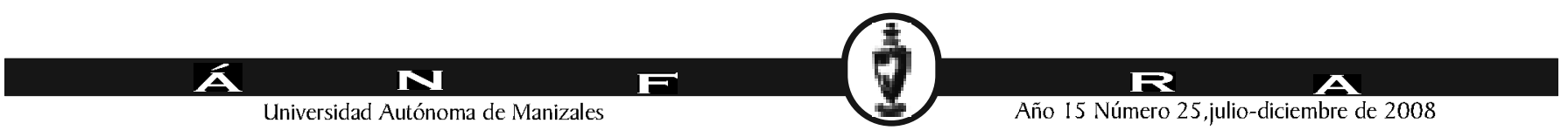



manera activa en el mundo en el que viven y transformarlo. La segunda, va más allá de la alfabetización y la educación básica. Se trata de ampliar y diversificar de manera considerable la educación continua para los sectores de mayor vulnerabilidad e integrarla a todas las estrategias de oferta educativa oficiales y las oportunidades que ofrece la educación para el trabajo y el desarrollo humano, como opción para ingresar a la educación superior.

Por último, se insistirá en el fortalecimiento de la Política de Educación Rural - PER -, aprovechando la formación de educadores, dotación de materiales pedagógicos, recursos para Proyectos Pedagógicos Productivos - PPP - y lo mas significativo, ocho propuestas pedagógicas autorizadas por el Ministerio de Educación Nacional: Escuela Nueva, Postprimaria, Telesecundaria, Sistema de Aprendizaje Tutorial SAT, Aceleración del Aprendizaje, Preescolar Desescolarizado, Preescolar Escolarizado, y Educación Media Rural.

\section{Escuela Que Educa Con Calidad ${ }^{20}$}

\begin{tabular}{|c|c|}
\hline Componente & $\begin{array}{l}\text { Meta del } \\
\text { cuatrienio }\end{array}$ \\
\hline Nuevos cupos en Educación básica & 7.852 \\
\hline Continuidad de cupos atendidos & 11.200 \\
\hline Nuevos cupos en educación media & 2.113 \\
\hline Nuevos cupos en población vulnerable & 5.000 \\
\hline Jóvenes, mujeres y educadores capacitados en el exterior. & 1.000 \\
\hline Sedes educativas mejoradas en su infraestructura fisica & 586 \\
\hline Establecimientos educativos ampliados con espacios pedagógioos especializados & 10 \\
\hline Insttuciones y centros educativos dotados & 243 \\
\hline Población escolar 1 y 2 del sisben asistidos con programas de bienestar escolar anualmente & 63.000 \\
\hline $\begin{array}{l}\text { Sedes Educativas incluidas en el SISTEMA INTERACTIVO DE CONSULTA DE } \\
\text { INFRAESTRUCTURA EDUCATIVA - SICIED. }\end{array}$ & 1.950 \\
\hline $\begin{array}{l}\text { Insttuciones Educativas favorecidas con recursos del FONDO DEPARTAMENTAL DE } \\
\text { GRATUIDAD Y COMPENSACIÓNEDUCATIVA - FOOGCE - (Anual) }\end{array}$ & 243 \\
\hline $\begin{array}{l}\text { Estudiantes favorecidos con el PROGRAMIA DE SEGUIMIENTO ACADEMICO, ASISTENCIA } \\
\text { ESCOLAR Y PREVENCIÓN DE PROBLEMAS SOCIALMENTE SIGNIFICATIVOS }\end{array}$ & 19.300 \\
\hline Jóvenes y Adultos Alfabetzados & 40.000 \\
\hline $\begin{array}{l}\text { Insttuciones y Centros Educativos desarrollando el PROGRAMA ESCUELA DE PADRES Y } \\
\text { AMIGOS DE LA ESCUELA - PEPAE- }\end{array}$ & 243 \\
\hline Sedes educativas rurales fortalecidas con el proyecto PER & 1.700 \\
\hline
\end{tabular}

El fundamento pedagógico de este programa es la calidad de la educación. Los alcances, rutas, estrategias, recursos y todo elemento fundamental para la creación y sostenibilidad de un Sistema de Aseguramiento de la Calidad que convoque a las instituciones educativas y a la ciudadanía en general a redireccionar el propósito educativo, para lograr mayor pertinencia y significado, como condición esencial para alcanzar competitividad y desarrollo sostenible en un mundo cada vez más globalizado.

\section{Escuela para la Sociedad del Conocimiento y la Información.}

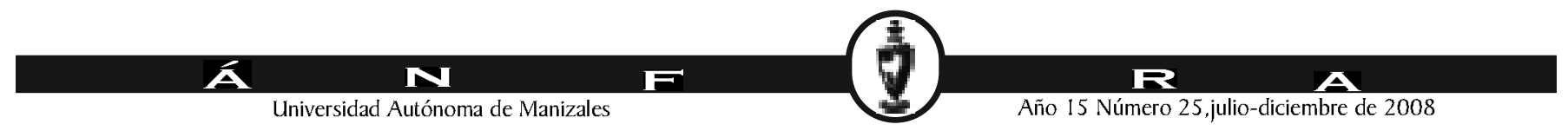


En la práctica está surgiendo un nuevo modelo de sociedad que demanda un nuevo modelo de escuela o dicho con más claridad reclama la Refundación de la Escuela y su revolución desde el conocimiento. Por ello, la actitud de la escuela, debe corresponder, desde su práctica pedagógica y curricular, con nuevas posturas. Una de ellas corresponde con las exigencias de la sociedad del conocimiento y la información. En primer lugar, es preciso tener de vista que en sociedades de cambios rápidos y vertiginosos es necesario el aprendizaje permanente (no basta la formación permanente) desde la propia práctica profesional. Por ello se hablara de organizaciones que aprenden, de comunidades profesionales de aprendizaje, de organizaciones inteligentes, de inteligencia organizativa, de talento organizacional, de capital humano,... y todo ello desde un pensamiento sistémico que implica: ver la totalidad mas que los detalles; dominio personal como persona, ciudadano y trabajador; modelos mentales institucionales; visión y misión compartidas y aprendizaje en equipo, entendidos como disciplinas de una organización inteligente y que aprende. La demanda fundamental a la Escuela Refundada seria una transición clara y rápida (no se puede esperar) hacia modelos de aprendizaje - enseñanza en el marco de un nuevo paradigma socio-cognitivo.

Recuperar la educación y disponerla de manera más efectiva hacia propósitos sociales bien definidos, para una sociedad del conocimiento y la información, implica: 1. Una nueva comprensión del conocimiento. 2. Desarrollo de herramientas para aprender y seguir aprendiendo de manera permanente, 3. Desarrollo sistemático de nuevas formas de aprender a aprender, 4. Objetivos por capacidades y valores y 5 . Profesor mediador del aprendizaje.

\section{Educación Ciencia y Tecnología}

En la Agenda Regional de Ciencia y Tecnología del Tolima se enuncian como debilidades del sector educativo para la generación de desarrollo regional: la fragmentación en la formación ofrecida por las instituciones educativas; una educación no pertinente en lo local; planes formulados a corto plazo y la ausencia de meritocracia en los cargos públicos del sector. Todo esto aunado a la poca participación del sector privado en la consolidación de sinergias hacia el desarrollo de capacidades intelectuales y el dominio de herramientas tecnológicas que permitan el avance en la ciencia y la tecnología, no han permitido la constitución de capitales y factores de producción de riqueza. EI desarrollo científico y tecnológico es factor fundamental para el crecimiento económico y la superación de los niveles de pobreza de la región. Por lo tanto, una política de ciencia y tecnología integral que involucre a todos los sectores de la actividad del departamento genera condiciones para el desarrollo regional. Al sector educativo le corresponde un papel protagónico en el desarrollo científico y tecnológico, pues del tipo de educación que se ofrezca y la forma como se organice el sistema depende la cantidad y calidad de las personas que se dediquen a la generación de desarrollos tecnológicos.

En este sentido, estamos en mora de convocar a los docentes y la academia en general a iniciar y concluir las discusiones que permitan fortalecer la Agenda de Ciencia y Tecnología y el Sistema de Formación Tecnológica y educación superior y formación para el trabajo- SFT - para que en los próximos cuatro años los niños, niñas, adolescentes y jóvenes tolimenses sean sensibles a identificar problemas concretos

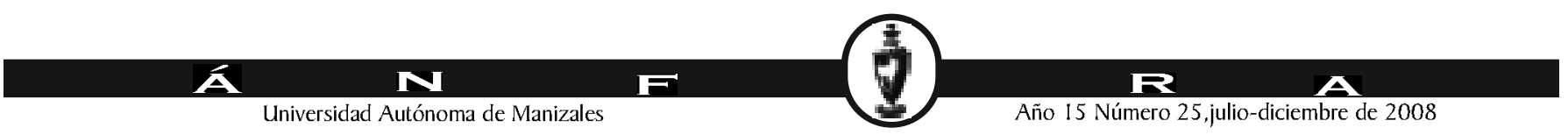


que hacen parte de su cotidianidad y se motiven en la búsqueda de explicaciones y soluciones.

\begin{tabular}{|c|c|}
\hline Componente & $\begin{array}{l}\text { Meta del } \\
\text { cuatrienio }\end{array}$ \\
\hline Docentes vinculados a programas de formación virtual & 2.500 \\
\hline Bachilleres con certificación laboral expedida por el Sena. & 1.500 \\
\hline Proyectos de investigación desarrollados por estudiantes & 500 \\
\hline Instituciones educativas que desarrollan la cátedra de emprendimiento & 243 \\
\hline Docentes formados en un segundo idioma ${ }^{15}$ & 2.000 \\
\hline Instituciones educativas con Internet15 & 243 \\
\hline Nümero promedio de estudiante por computador & 24 \\
\hline Docentes en proceso de formación permanente & 2.100 \\
\hline $\begin{array}{l}\text { Municipios que acompañan la apropiación de onientaciones pedagógicas en las diferentes } \\
\text { modalidades de atención educativa a la primera infancia }\end{array}$ & 46 \\
\hline $\begin{array}{l}\text { Porcentaje de establecimientos educativos oficiales desarrolando actividades de aula } \\
\text { basadas en estándares básicos y competencias }\end{array}$ & $100 \%$ \\
\hline $\begin{array}{l}\text { Puntaje promedio departamental en las pruebas SABER (promedio ponderado de las áreas } \\
\text { y grados evaluados) }\end{array}$ & 58 \\
\hline $\begin{array}{l}\text { Puntaje promedio departamental en las áreas del núcleo común del examen de Estado } \\
\text { (promedio general de todas las áreas evaluadas del núcleo común) }\end{array}$ & 48 \\
\hline $\begin{array}{l}\text { Instituciones educativas ejecutando Planes de mejoramiento institucional con asistencia } \\
\text { tècnica de la Secretaria de educación }\end{array}$ & 243 \\
\hline $\begin{array}{l}\text { Porcentaje de establecimientos de bojo logro acompafiados en la formulación de Planes de } \\
\text { Mejoramiento Institucional }\end{array}$ & $100 \%$ \\
\hline $\begin{array}{l}\text { Experiencias significativas que fortalecen competencias básicas acompanadas a través de } \\
\text { redes de aprendizaje }\end{array}$ & 46 \\
\hline Instituciones educativas integrando los ejes transversales en sus PEl. & 243 \\
\hline $\begin{array}{l}\text { Instituciones Educativas ejecutando EL PROGRAMA DE EDUCACION PARA LA PAZ, LA } \\
\text { CONVIVENCIA LA CIUDADANIA. }\end{array}$ & 243 \\
\hline Instituciones Educativas ejecutando EL PROGRAMA DE EDUCACIÓN AMBIENTAL & 243 \\
\hline Instituciones Educativas participando Planes de Formación & 243 \\
\hline $\begin{array}{l}\text { Escuelas Normales Superiores acompanadas con estrategias de aseguramiento de la } \\
\text { calidad y planes de mejoramiento }\end{array}$ & 3 \\
\hline $\begin{array}{l}\text { Estudiantes con necesidades educativas especiales atendidos con modelos pedagógioos } \\
\text { flexibles }\end{array}$ & 2380 \\
\hline Estudiantes de poblaciones étricas atendidos con modelos pedagógicos propios y flexibles. & 10.720 \\
\hline $\begin{array}{l}\text { Porcentaje de instituciones de educación media académica con oferta de formación en } \\
\text { competencias laborales generales }\end{array}$ & $100 \%$ \\
\hline $\begin{array}{l}\text { Porcentaje de instituciones de educación media articulados con programas lécnicos y } \\
\text { tecnológicos }\end{array}$ & $50 \%$ \\
\hline
\end{tabular}

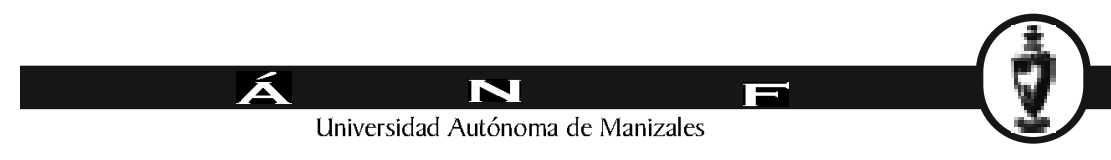




\begin{tabular}{|c|c|}
\hline $\begin{array}{l}\text { Programas de formación para el trabajo y el desarrollo humano certificados por la } \\
\text { Secretaria de Educación }\end{array}$ & $100 \%$ \\
\hline Institucoones de educación para el trabag certificadas por la Sectetaria de educación. & 10050 \\
\hline Porcentaje de instituciones de educación media técrica arbculados oon el SENA & 1009 \\
\hline $\begin{array}{l}\text { Porcentaje de instuciones de educación media téonica con oferta de formacich en } \\
\text { ocmpetencias labotales especificas }\end{array}$ & $100 \%$ \\
\hline Alianzas entre las instituciones de educación meda y el sector productivo & 8 \\
\hline
\end{tabular}

\section{Escuela que lidera el desarrollo local ${ }^{21}$}

Un servicio educativo de calidad exige procesos de modernización y reingeniería, que fortalezcan la institucionalidad en todos sus escenarios, sectores y dependencias, para que desde allí se jalonen procesos de desarrollo local que impacten en la comunidad, especialmente en las familias. Los procesos de modernización, liderados por el Ministerio de Educación Nacional, buscan que el sistema educativo pueda garantizar a todos los niños, niñas y jóvenes en edad escolar su derecho a la educación básica (Acceso, permanencia y altos niveles de calidad y pertinencia). Para ello, el Departamento del Tolima en convenio con el Ministerio de Educación impulsa y avanza en la transformación de la gestión del sector con el fin de alcanzar la mayor efectividad del servicio educativo.

En el cuatrienio, las acciones del gobierno se dedicarán al fortalecimiento de la institucionalidad desde el escenario propio y real de las instituciones y centros educativos, hasta las dependencias encargadas de organizar y dirigir la prestación del servicio educativo a la comunidad tolimense. El propósito final es lograr una mayor efectividad en el ejercicio del derecho a la educación y desde allí direccionar el accionar de la comunidad y liderar el desarrollo local.

Así mismo, se apoyará la gestión y organización escolar y el desarrollo de procesos que conduzcan a las instituciones hacia sistemas educativos más inclusivos y escuelas más plurales y democráticas. La institucionalidad también se verá favorecida si se empieza a generar cambios en la estructura y el clima organizacional de los establecimientos educativos. El clima organizacional en las escuelas debe ocupar un lugar destacado en el desarrollo de la vida institucional. Distintos modelos de eficacia escolar ubican el clima entre los factores de eficacia y equidad. En los próximos cuatro años se insistirá en lograr una mayor eficiencia en la gestión, consistencia, transparencia, rendición de cuentas y un compromiso irrestricto con el derecho a la educación como finalidad central del accionar público, recuperar la confianza en el sector y, por último, lograr que la comunidad participe de manera decidida en la construcción de tejido social desde el escenario escolar. Todo lo anterior, consolidado en un Sistema Local de Educación, como estrategia para el fortalecimiento y autonomía municipal, que reúna y sintetice el conjunto de prioridades, proyecciones, responsabilidades y competencias en la prestación del servicio educativo.

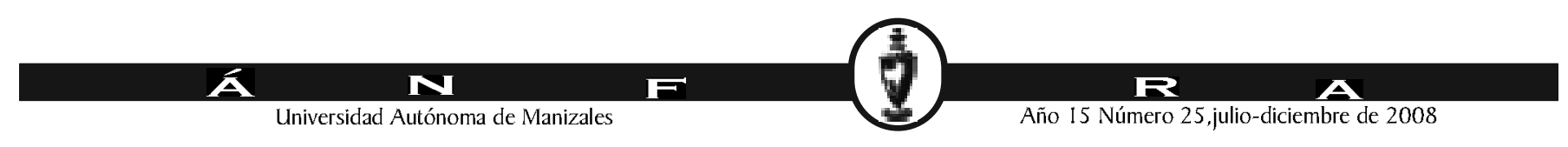


RESULTADOS ESPERADOS :

\begin{tabular}{|c|c|c|c|}
\hline OBJETIVO & Indicador & Línea base & Meta del Cuatrienio \\
\hline $\begin{array}{l}\text { Fortalecer la apertura de } \\
\text { la escuela a la comunidad } \\
\text { v crear condiciones } \\
\text { sostenibles para el } \\
\text { ejercicio pleno del } \\
\text { derecho a la educación, } \\
\text { con el fin de mejorar la } \\
\text { calidad de vida, reducir la } \\
\text { pobreza y la inequidad, } \\
\text { potenciar el desarrollo } \\
\text { autónomo, social y } \\
\text { comunitario de toda la } \\
\text { comunidad tolimense. }\end{array}$ & $\begin{array}{l}\text { Provectos educativos de media } \\
\text { técnica articulados a necesidades } \\
\text { reales de la comunidad. } \\
\text { Secretaría de Educación con } \\
\text { procesos en línea con el MEN. } \\
\text { (Matricula, recursos humanos, } \\
\text { recursos financieros, calidad } \\
\text { educativa y servicio al ciudadano). } \\
\text { Municipios con sistemas } \\
\text { Educativos Locales -SEL- } \\
\text { operando. }\end{array}$ & 32 & 88 \\
\hline
\end{tabular}

\section{Fortalecemos la Institucionalidad Educativa}

En los próximos cuatro años se apoyará la gestión administrativa, la organización escolar y el desarrollo de procesos que conduzcan a las instituciones hacia sistemas educativos más inclusivos y escuelas más plurales y democráticas. La inclusión busca asegurar para toda la población el derecho a una educación de calidad, pues existe un alto porcentaje de niños, niñas y jóvenes, además de aquellos con discapacidad, que tiene negado este derecho. La inclusión está relacionada con el acceso, la participación y logros de todos los alumnos, con especial énfasis en aquellos que están en riesgo de ser excluidos o marginados.

Es preciso aplicar principios de la plantación estratégica que den cuenta de la efectividad de las políticas y estrategias adoptadas para la prestación del servicio educativo e incorporar el tema de gestión por resultados. Las instituciones educativas del departamento están en mora por preguntarse y generar respuestas a dos fenómenos que hacen parte de su vida escolar: la pérdida o reprobación escolar y los efectos que origina una ineficiencia en la gestión escolar. Necesitamos con urgencia un sistema escolar orientado exclusivamente por la garantía del derecho a la educación, que ir acompañado de una reasignación de las plazas docentes en función de la distribución de la matricula, una reglamentación efectiva a la movilidad o traslado de los docentes y una reorganización al sistema de organización escolar previsto para la prestación del servicio educativo.

\section{Modernizamos el Sector y Alcanzamos Efectividad.}

El fortalecimiento de los sistemas de información constituye una fuente indispensable para mejorar la gestión del sistema educativo y una importante herramienta para que los ciudadanos ejerzan sus derechos de vigilancia y control de los asuntos públicos. De ahí la importancia que las instituciones educativas, como entidades del sector público incorporen en los Proyectos Educativos Institucionales acciones dirigidas hacia la consolidación de un sistema de gestión de la calidad. Trabajen en procura de generar una cultura de calidad principalmente con la identificación de su cadena de valor y la gestión de sus procesos y procedimientos.

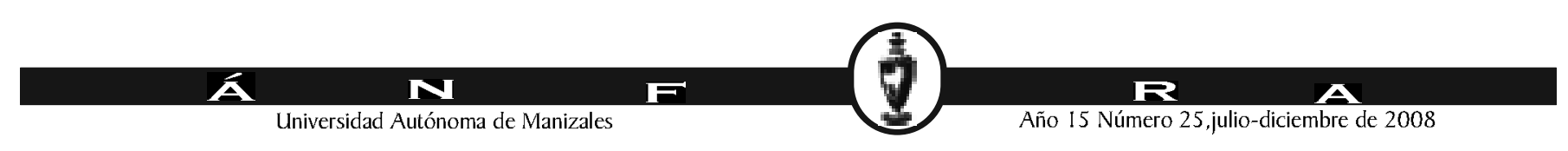




\section{Establecemos y recuperamos relaciones de confianza.}

La confianza genera capital social y este a su vez genera desarrollo económico. Esta afirmación puede explicarse porque quien confía es consciente de las capacidades, actitudes y aptitudes de la persona en quien deposita su confianza, por esta razón dirige estos elementos de la mejor forma para conseguir un objetivo común, ya sea delegando funciones o trabajando en equipos homogéneos o heterogéneos, donde cada uno hace su mejor esfuerzo para lograrlo. Recuperar espacios de confianza con la comunidad exige una educación distinta. Por tal razón, se espera que la ciudadanía tolimense lea en sus instituciones educativas organizaciones sociales de cara a las necesidades de la comunidad y en consecuencia, participe de manera decidida en la construcción de tejido social.

\section{Construimos un Sistema Educativo Local - SEL -}

En los próximos cuatro años asumimos el reto de construir Sistemas Educativos Locales - SEL - en cada uno de los municipios no certificados en educación, entendido el SEL como una estrategia orientada a dar soluciones y mejorar la prestación oportuna y adecuada de los servicios de educación que el Estado debe garantizar para toda la población, o como conjunto de servicios educativos integrados e interrelacionados en un espacio geográfico en el cual el Estado y la comunidad local actúan conjuntamente para el desarrollo de la educación en sus diversos niveles y manifestaciones. Una tarea inaplazable, para lograr la organización de SEL funcionales y efectivos, consiste en la reorganización de las Juntas Municipales de Educación - JUME - y la Junta Departamental de Educación - JUDE.

Lograr resultados exitosos que generen impactos duraderos en la educación de los tolimenses requiere de un buen conjunto de estrategias, diseñadas y dirigidas a propósitos concretos. Además del Sistema de Información y el Plan de Modernización del Ministerio de Educación Nacional, la rendición de cuentas surge como una opción para acercar todos los agentes educadores del sistema escolar. De igual forma es preciso considerar que una de las mayores debilidades encontradas en el sector educativo es la carencia de estudios sistemáticos que analicen aspectos nodales de la educación en el departamento y reporten cifras reales que indiquen la cobertura del servicio educativo en los niveles preescolar, basica, media y superior, la atención a sectores de la población considerados de mayor vulnerabilidad, como son: los discapacitados, desplazados, desmovilizados, indígenas, iletrados, adolescentes en conflicto con la ley, niños, niñas y adolescentes en protección, entre otros. Para superar estas debilidades se adelantarán investigaciones cualitativas y cuantitativas donde participen docentes, directivos y la comunidad de cada localidad. 


\begin{tabular}{|l|c|}
\hline \multicolumn{1}{|c|}{ Componente } & Meta del Cuatrenio \\
\hline Foros educativos departamentales & 4 \\
\hline $\begin{array}{l}\text { Proyectos productivos de las instituciones educativas del depa rtamento acompañadas en } \\
\text { su idea de negocio }\end{array}$ & 46 \\
\hline Proyectos Pedagógicos Productivos ejecutados por la comunidad & 250 \\
\hline Reuniones locales para rendición de cuentas (anuales) & 46 \\
\hline Investigación cuantitativa y cualitativa en aspectos nodales del sector educativo & 3 \\
\hline Sistema de Inspección y Vigilancia de la Educación & 1 \\
\hline
\end{tabular}

\section{Educación Superior Y Formación Para El Trabajo ${ }^{22}$}

Un nuevo reto para el sector educativo es el fortalecimiento de la educación superior en sus distintas modalidades. En este escenario se considera población objetivo los jóvenes cuya edad se encuentra entre los 18 y 24 años. Según las proyecciones del DANE este rango de población pasará de 160.122 jóvenes en el año 2007, a 177.224 en el año 2011. Un año después la curva demográfica de este rango de edades iniciará la fase descendente. Esta circunstancia implica que las mayores acciones en el incremento de la cobertura de educación superior deberán ser implementadas de inmediato, pues de lo contrario la brecha entre el Tolima y la nación se incrementará.

Consecuentes con el propósito, claro en empleo y en economía, de superar la brecha departamental respecto a la nación, esto es anular los efectos sobre la economía y la sociedad, se propone ampliar la cobertura en educación superior, por lo menos al 35\%. Hoy la cobertura muestra un $22 \%$. Se comprende la necesidad de enfatizar en un gran esfuerzo por incrementar la cobertura de educación superior en sus distintas modalidades. Dado que el objetivo de elevar el nivel educativo es permitir ocupación e ingresos dignos que modifiquen lo especificado en el tema de desempleo - $80 \%$ de los ocupados con menos de 2 salarios mínimos y $50 \%$ con un salario mínimo o menos y una gran informalidad - la capacitación laboral que conduzca a certificación de competencia laboral se constituye en una estrategia complementaria.

Tres razones fundamentales motivan la necesidad expuesta sobre el incremento de la cobertura en educación superior: la primera, el escape de las trampas de pobreza que encuentra en la educación superior la salida y así lo entienden los ciudadanos que cifran en ella la única posibilidad de ascenso social, la segunda, la ya anotada sobre su

\section{Grafica 11}
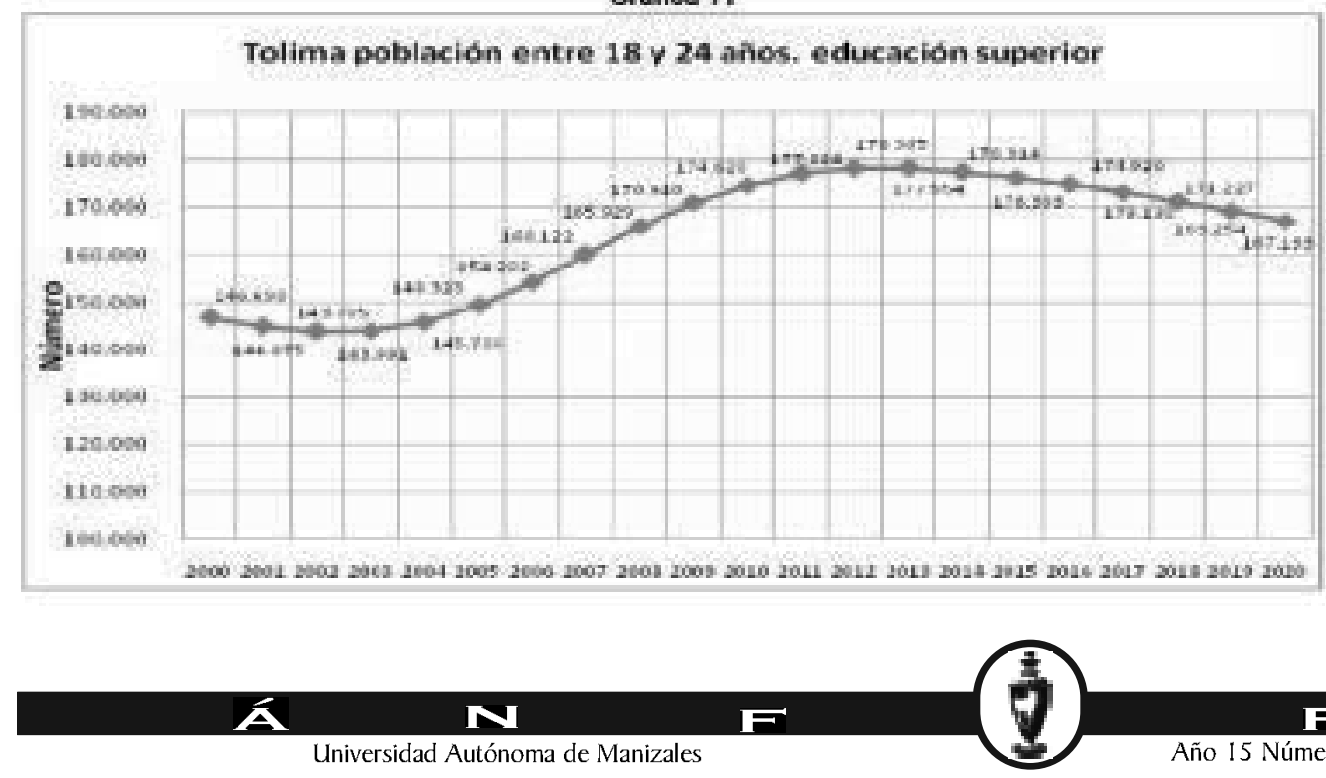
Universidad Autónoma de Manizales 
influencia en el índice de desempleo y descongestión del mercado laboral del Tolima y, la tercera que es de importancia capital para nuestra economía: los efectos sobre la competitividad de la estrategia.

Según estudios de la CEPAL sobre competitividad, el Tolima ocupa el puesto once entre veintitrés departamentos de Colombia. Esta situación ha sido repetitiva en los últimos años, lo cual refleja que las diferentes políticas que se han venido desarrollando desde hace más de una década no han mejorado sustancialmente la competitividad del departamento. Uno de los principales factores que ha incidido negativamente en la competitividad del departamento del Tolima está dado en que el Recurso Humano no responde a las potencialidades del territorio, y el cual según el estudio de la CEPAL ocupa la posición 22 de los 23 departamentos analizados.

De acuerdo con la Comisión Nacional de Competitividad, las principales conclusiones por las cuales Colombia y las regiones no son competitivas, obedece a los siguientes aspectos:

i) El principal problema de la falta de competitividad en Colombia es la baja productividad, principalmente asociada con la informalidad.

ii) Las principales diferencias en el grado de competitividad de los países se explican por diferencias en la productividad.

iii) Las políticas educativas (y de desarrollo de destrezas laborales) deben hacer parte de una estrategia integral dirigida a aumentar la competitividad.

iv) La extensión de la educación superior es un camino hacia la formalización...

v) Colombia requiere una transformación productiva que implica el surgimiento de nuevas actividades y la ubicación en nichos más sofisticados dentro de los sectores tradicionales. Esto conlleva un cambio sustancial en la demanda de destrezas laborales y de recursos humanos estratégicos. Si no se generan dichas ofertas la transformación productiva no podrá llevarse a cabo.

vi) Las respuestas a estas necesidades educativas, y la provisión de otros bienes públicos específicos, requieren de un alto grado de coordinación público-privada. Esta coordinación debe ser llevada y operacionalizada a nivel de las regiones. De acuerdo con lo anterior, el departamento del Tolima le apostará a una estrategia integral que propenda por el aumento de los niveles de calidad y productividad para así generar competitividad, a partir de la ampliación de los niveles de educación mediante la oferta de un programa de apoyos que busca darle oportunidad a un mayor número de Tolimenses de continuar sus niveles de calificación y cualificación mediante la financiación de educación pertinente y de calidad.

Así mismo la oferta académica deberá estar a la vanguardia de los cambios que se han venido dando a través de los tiempos a partir de la globalización y los desarrollos tecnológicos, articulada tanto a las demandas actuales como futuras que se requieren para el desarrollo de los sectores productivos regionales, nacionales e internacionales mediante la integración de actores que busquen la construcción de la competitividad regional.

\section{Una Oportunidad para el Desarrollo de Nuestra Juventud Tolimense}

Desde el gobierno, SOLUCIONES PARA LA GENTE, se liderara el fortalecimiento de la educación superior, para que los jóvenes contribuyan al impulso de la economía y

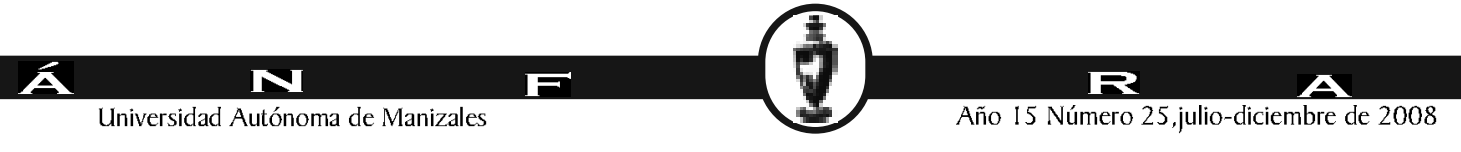




\begin{tabular}{|l|l|c|c|}
\hline OBJETIVO & Indicador & Línea base & Meta del cuatrenio \\
\hline $\begin{array}{l}\text { Desatar un proceso de } \\
\text { ampliación de las oportunidades } \\
\text { reales para la juventud del }\end{array}$ & & $\mathbf{2 2 , 0 0 \%}$ & $\mathbf{3 4 , 5 \%}$ \\
$\begin{array}{l}\text { Tolima que permita el encuentro } \\
\text { de opciones atractivas y }\end{array}$ & $\begin{array}{l}\text { Cobertura en Educación } \\
\text { dignificantes, para la }\end{array}$ & & \\
$\begin{array}{l}\text { construcción de sus proyectos de } \\
\text { vida. }\end{array}$ & & & \\
\hline
\end{tabular}

generen el desarrollo en cada una de sus provincias. Alcanzar niveles de desarrollo exige una transformación cultural y el afianzamiento del sentido de pertenencia, para que el tolimense valore el conocimiento y el trabajo productivo, se identifique con su comunidad y su región y tenga una visión positiva del futuro, como colombiano y como ciudadano del mundo.

Alcanzar estos niveles de desarrollo exige al sistema educativo incorporar desde sus ofertas educativas iniciales propuestas coherentes y reales que señalen rutas de éxito. En los próximos cuatro años los esfuerzos se dirigirán al desarrollo de estrategias que incorporen nuevos modelo de pertinencia educativa para contribuir a la competitividad regional, cuyo propósito es ofrecer apoyos para que quienes se vinculen a la educación superior y a la educación para el trabajo y el desarrollo humano en el departamento del Tolima, cuenten con el apoyo de las instituciones educativas regionales comprometidas con los desafíos del departamento, mediante la oferta de programas académicos pertinentes bajo metodologías presenciales y a distancia. La asignación de los cupos para la educación Superior, para el trabajo y el desarrollo humano debe privilegiar la vinculación de las instituciones públicas. Desde este escenario se busca desde lo regional aportar a:

$\varnothing$ Elevar la tasa de asistencia escolar, evitar la deserción y poder reducir la participación laboral de los estudiantes

$\varnothing \quad$ Elevar la pertinencia laboral de la educación media técnica

$\varnothing$ Disminuir las tasas de desempleo mediante una oferta focalizada hacia carreras cortas, técnicas y tecnológicas pertinentes a necesidades reales del sector productivo

$\varnothing$ Aumentar la calidad de la educación en el departamento

$\varnothing \quad$ Fomentar los procesos de certificación de competencias laborales

$\varnothing$ Contribuir al mejoramiento de la calidad de los docentes de las instituciones educativas

$\varnothing$ Fortalecer la infraestructura física y tecnológica de las instituciones educativas

$\varnothing$ Rediseñar los currículos para la inclusión de competencias claves que se demandan en los profesionales

$\varnothing$ Aumentar la interacción empresarial durante el proceso de formación 


\begin{tabular}{|l|c|}
\hline \multicolumn{1}{|c|}{ Componente } & $\begin{array}{c}\text { Meta del } \\
\text { cuatrienio }\end{array}$ \\
\hline Nuevos cupos en educación superior ${ }^{16}$ & 20.000 \\
\hline Jóvenes, mujeres y educadores capacitados en el exterior ${ }^{199}$ & 1.000 \\
\hline $\begin{array}{l}\text { Subsidios otorgados a estudiantes del nivel 1 y } 2 \text { del SISBEN para el acceso a la } \\
\text { educación superior }\end{array}$ & 1.000 \\
\hline Centros Regjonales de educación Superior - CERES - Fortalecidos & 9 \\
\hline Instituciones de Educación Media Técnica desarrollando ciclos propedéutioos & 46 \\
\hline $\begin{array}{l}\text { Programas de de Educación Virtual para el fortalecimiento de la Educación Superior } \\
\text { apoyados por el Departamento }\end{array}$ & 4 \\
\hline $\begin{array}{l}\text { Apoyos financieros a través del ICETEX u otra entidad estatal o privada para el ingreso a la } \\
\text { Educación Superior }\end{array}$ & 1.500 \\
\hline Empresas asociativas juveniles con plan de negocios & 46 \\
\hline Planes de provinciales de desarrollo empresarial & 10 \\
\hline Construcción de la visión de futuro & 10 \\
\hline Creación de Centros Regionales de Educación Superior - CERES - & 3 \\
\hline Culminación integral del proyecto de Formación Tecnologica para el Trabajo & 46 \\
\hline
\end{tabular}

En este eje, la política 4 es la correspondiente a Políticas Transversales, la cual involucra acciones específicas dirigidas a niñez y adolescencia, juventud, grupos étnicos y mujer.

En el eje II se incluyen todos los componentes relacionados con el propósito de apostarle a la competitividad económica, orientando acciones tanto a la articulación intradepartamental como hacia los circuitos nacionales e internacionales de la economía, a partir del desarrollo de la infraestructura para la movilidad, la provisión de servicios públicos, el fortalecimiento empresarial y el desarrollo del sector base de la producción agropecuaria.

En el eje III, aún muy débil en el conjunto del plan, la gestión ambiental con enfoque social y la gestión del riesgo constituyen los dos propósitos directos, en cuya ejecución se conjugan acciones de coordinación con la autoridad ambiental regional y con las instancias nacionales del sector.

Finalmente, en el eje IV, se incluyen los componentes de la planificación integral del desarrollo regional y la gestión hacendaria y fiscal financiera de la entidad territorial. En este eje se hace explícita la recuperación del rol del Departamento Administrativo de Planeación en la conducción de las acciones de coordinación de las políticas de desarrollo integral del departamento, en estrecha coordinación y apoyo a las entidades territoriales municipales y con interlocución directa con el Departamento Nacional de Planeación y el Ministerio de Hacienda. El desarrollo regional aboca el tratamiento de las agendas municipales, con relación directa con los planes de desarrollo municipal, la asociatividad municipal alrededor de proyectos estratégicos de interés común y, las relaciones interdepartamentales, relacionadas con las propuestas de integración y cooperación regional de las regiones Centro, Eje Cafetero, Alto Magdalena, Suroccidente y Corazón de Colombia (Magdalena Medio).

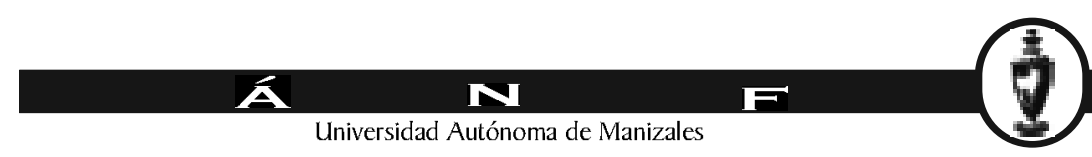
Universidad Autónoma de Manizales 
En desarrollo del propósito de generar consensos y acuerdos concertados entre los actores público, privado y comunitario, el gobierno departamental promueve y participa en las siguientes alianzas estratégicas:

- $\quad$ Agenda I bagué - Tolima.

- Círculo de Competitividad Turística del Tolima.

- Tolima Socialmente Responsable.

- $\quad$ Pacto por la Infancia, la Adolescencia y la J uventud.

A escala departamental se ha retomado el proceso de la asociatividad municipal, encontrándose en camino los procesos de las Provincias del Suroriente, Oriente y Sur del Tolima. ${ }^{26}$

\section{La financiación de los ODM}

En el texto del Plan de Desarrollo, en el aparte correspondiente a las finanzas públicas departamentales se lee:

Como medidas tendientes a mejorar las arcas departamentales, el gobierno actual se ha propuesto mantener las medidas de ajuste fiscal, buscando además dar cumplimiento al indicador de la Ley 617 de 2000, relacionado con los gastos de funcionamiento. Expresa el Plan al respecto: “En ese sentido, es necesario adoptar medidas conducentes a lograr la eficiencia necesaria en el recaudo y el manejo ponderado de los escasos recursos".

Entre las estrategias que en tal sentido se han diseñado, figuran la venta o entrega en dación de pago de aquellos bienes muebles e inmuebles improductivos para el ente territorial..., captando recursos que se destinaran de conformidad con la Ley y el Acuerdo y por otro lado, los que se entreguen en dación de pago, el Departamento interrumpe el pago de impuestos y de gastos de administración y funcionamiento. Se realizará un seguimiento a todos los procesos litigiosos en contra del Departamento, con miras a recuperar títulos judiciales y remantes de embargos con destino al tesoro departamental. Se llevará a cabo la depuración del rezago presupuestal.

Los rendimientos financieros por los dineros que la Tesorería General del Departamento deposite en las Entidades Financieras debe convertirse en una de sus principales rentas, por esta razón se estructurara una óptimo portafolio de inversiones con las tasas de interés preferenciales del mercado. Será objetivo permanente del Gobierno gestionar recursos del Presupuesto Nacional de los fondos concúrsales, con proyectos técnicamente viables, como fuente de financiación a la inversión; en este sentido la gestión del Departamento ha sido excesivamente pobre, con relación a otras regiones y hemos dejado de percibir recursos con los cuales la Administración hubiere podido

\begin{tabular}{|l|c|c|}
\multicolumn{1}{|c|}{ OBJETIVO } & Línea base & Meta del cuatrienio \\
\hline Incremento en los Ingresos totales & $\begin{array}{c}\$ 616.670 \\
\text { millones }\end{array}$ & $\begin{array}{c}\$ 717.551 \\
\text { Millones }\end{array}$ \\
\hline Modernización del sistema tributario & $\mathrm{N} . \mathrm{E}$ & $\begin{array}{c}1 \text { Dirección } \\
\text { modernizada }\end{array}$ \\
\hline Estados Financieros Depurados & $80 \%$ & $100 \%$ \\
\hline Rezago presupuestal depurado & $35 \%$ & $100 \%$ \\
\hline
\end{tabular}

\section{E N} Universidad Autónoma de Manizales
26 El 17 de octubre, en un Encuentro con participación de alcaldes, concejales y líderes sociales y gremiales, se firmó el Acuerdo de Voluntades para promover el proceso asociativo de los municipios de la Provincia del Oriente tolimense, suscrito por los mandatarios de Villarrica, Icononzo, Cunday, Carmen de Apicalá y Melgar, actuando como garante del Acuerdo el Gobernadordel Tolima.

Año 15 Número 25,julio-diciembre de 2008 
En términos de "Gestión tributaria para el fortalecimiento de la inversión social del Departamento del Tolima. El Propósito de la Gestión Tributaria está orientado al incremento de los ingresos del Departamento, mediante la eficiencia en el recaudo y un efectivo control de los impuestos, de tal manera que el Gobierno Departamental cuente con los recursos para dar cumplimiento a su objeto social".

En otro frente, aunque muy deprimido de las finanzas de la entidad territorial, se encuentra la reorientación de las Ilamadas empresas industriales y comerciales del Departamento, que son en este caso la Fábrica de Licores y la Lotería del Tolima, las cuales requieren de "un ejercicio serio y responsable en materia administrativa, financiera y económica para así poder cumplir con el desarrollo económico, la inversión social que requiere los tolimenses específicamente en los sectores de salud y educación".

I gualmente se espera redireccionar los controles al Concesionario de Apuestas Permanentes, lo cual junto a los rendimientos o la mejoría en el manejo que se dé a la Fábrica de Licores y a la Lotería, permitirán una mejoría en las transferencias a la salud y la educación del departamento.

El comportamiento de la inversión para el cuatrienio 2008-2001 se estima a partir del comportamiento que ésta ha tenido a partir de 2004:

Con relación a la inversión se refleja un incremento promedio entre el año 2004 - 2007 del $53 \%$ es decir $\$ 81.787$ millones, representados en un crecimiento del $59 \%$ en el 2005 , del $45 \%$ en el 2006 y para el 2007 en el $56 \%$. El Fondo Educativo Departamental, considerado como inversión social en educación en el año 2005, presentó un crecimiento del 14\% respecto al año 2006, un crecimiento del $4 \%$ en el 2006 y del $5 \%$ en el 2007 , es decir que en promedio obtuvo un aumento del $7 \%$.

Los Gastos realizados por el Fondo de Salud, los cuales son atendidos con recursos de Rentas Cedidas, Sistema General de Participaciones y aportes nacionales para programas del sector, fueron de $\$ 65.077$ millones en el 2004, de $\$ 80.435$ millones en 2005 , de $\$ 102.760$ millones para el 2006 y de $\$ 110.572$ millones en el 2007. (Ver tabla 2 y Anexo 2 )

Los ingresos se proyectaron básicamente teniendo en cuenta el comportamiento histórico de las rentas con el fin de considerar valores más ajustados a la realidad y de esta manera contribuir al logro de las políticas departamentales establecidas en el Plan de Desarrollo 2008 - 2011 "Soluciones para la Gente". El Presupuesto oficial aprobado por la Asamblea Departamental para el 2008, ascendió a la suma de \$498.502 Millones, pero ha sido costumbre en la Administración Departamental a través de los años, elaborar presupuestos conservadores, para posteriormente modificarlo vía adiciones presupuéstales en la mayoría de los casos derivados de la incorporación del Superávit Presupuestal, de los rendimientos financieros y de los mayores recaudos que presentan algunos rentas del Departamento. Con estas consideraciones, se proyecta un presupuesto de ingresos al finalizar la vigencia de 2008 en cuantía de $\$ 616.670$ millones, superior al aforo inicial en un 24\% Para la Vigencia de 2009 al 2011 se considera un crecimiento promedio de los ingresos del $4.5 \%$ al pasar de $\$ 616.670$ millones a \$717.571 millones.

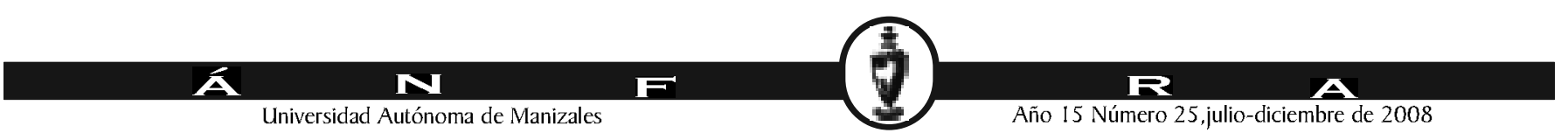




\begin{tabular}{|l|c|c|c|c|c|c|}
\hline \multicolumn{7}{|c|}{$\begin{array}{c}\text { PROYECCIONES DE INGRESOS 2008-2011 } \\
\text { (En Millones de \$) }\end{array}$} \\
\hline & 2008 & 2009 & 2010 & 2011 & $2009-2008$ & $2011-2010$ \\
\hline \multirow{2}{*}{ CONCEPTO } & & & & & & \\
\hline ING. CORRIENTES & 208.512 & 217.989 & 235.389 & 254.181 & $5 \%$ & $8 \%$ \\
\hline TRIBUTARIOS & 105.054 & 113.429 & 122.473 & 132.242 & $8 \%$ & $8 \%$ \\
\hline NO TRIBUTARIOS & 103.458 & 104.560 & 112.916 & 121.939 & $1 \%$ & $8 \%$ \\
\hline FONDOS ESPECIALES & 345.938 & 395.479 & 420.678 & 447.145 & $14 \%$ & $6 \%$ \\
\hline & & & & & & \\
\hline RECURSOS DE CAPITAL & 62.220 & 15.424 & 15.536 & 16.226 & $-75 \%$ & $1 \%$ \\
\hline & & & & & & \\
\hline TOTAL & 616.670 & 628.893 & 671.603 & 717.551 & $2 \%$ & $7 \%$ \\
\hline
\end{tabular}

Fuente: Secretaria de Hacienda - Dirección de Rertas

\section{NUEVAS METAS DE CRECIMIENTO}

El Gobierno de "Soluciones para la Gente" se propone romper el modelo de la Hacienda Pública Departamental empleado por las últimas administraciones que hace tiempo entró en crisis, porque se ha limitado a captar unos tributos que por ordenamiento jurídico les corresponde sin hacer ningún esfuerzo fiscal, los cuales algunos de ellos por variables del contexto nacional, han incoado la tendencia a la baja, sin levantar la mirada hacia el Presupuesto Nacional donde han recursos que pueden ser atraídos para la región mediante la presentación de proyectos técnicamente viabilizados.

En este sentido, el gobierno "Soluciones para la gente" se encuentra adelantando las gestiones para suscribir un Programa de Ajuste Fiscal y Financiero que de una parte le posibilite subsanar el incumplimiento reiterado de los indicadores establecidos en la Ley 617, y de otra, le permita acceder a los apoyos financieros específicamente, crédito, avales de la nación y cofinanciación que redundará en mayores posibilidades de inversión para el Departamento del Tolima dentro de su Plan de Desarrollo "Soluciones para la Gente 2008 - 2001" Será objetivo permanente del Gobierno el de gestionar recursos del Presupuesto Nacional de diferentes fuentes de financiación contenidos en la oferta institucional del nivel nacional y de los fondos concúrsales, con proyectos técnicamente viabilizados, como fuente de financiación a la inversión; en este sentido la gestión del Departamento ha sido excesivamente pobre, con relación a otras regiones y hemos dejado escapar recursos con los cuales la Administración seccional hubiera podido llegar con respuestas oficiales hacia la población más necesitada. Los recursos de capital representados en recursos del crédito, rendimientos financieros, venta de activos improductivos especialmente, serán fuente primordial en este Gobierno para desarrollar proyectos de inversión de impacto regional en beneficio de la comunidad tolimense.

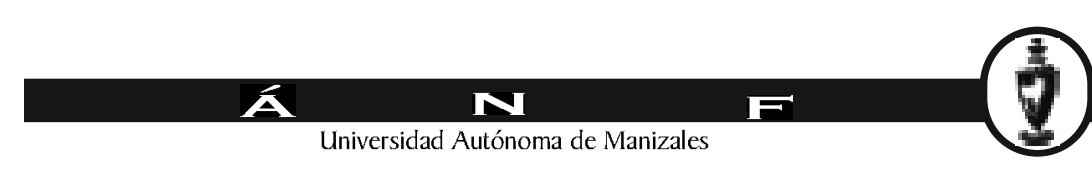




\section{Expectativas De Mayores Ingresos}

La actual coyuntura que vive los entes territoriales obliga que los administradores de la Hacienda Pública, enfocar sus esfuerzos para la captación de recursos sin depender únicamente de las rentas tradicionales para fortalecer los fiscos a través de otras fuentes.

En el caso concreto de la Gobernación del Tolima, existe una elevada cartera morosa de rentas como las multas del Instituto Departamental de Transito y de cuotas partes pensionales, sobre las cuales hasta el momento muy poco esfuerzo se ha hecho por recuperarla. En este sentido se conformara un equipo jurídico especializado durante el cuatrienio, que se dedicará a recuperar esos dineros que son de todos los tolimenses. Será tarea del mismo equipo jurídico el de recuperar títulos judiciales y remanentes de embargos que han quedado del sinnúmero de demandas a las que ha sido objeto la entidad. Aprovechando la política pública que el Gobierno Nacional trazó en el documento CONPES 3463 de marzo 12 de 2007, sobre los Planes Departamentales de Agua y Saneamiento se han buscado diferentes fuentes para financiar el plan en el Tolima y en ese propósito se tiene la expectativa de canalizar aportes a través de CORTOLIMA, recursos provenientes de las audiencias públicas correspondientes a $\$ 26.000$ millones para el cuatrienio de conformidad con el artículo 91 del Decreto Ley Nacional No 1151 (Plan Nacional de Desarrollo), crédito con la banca multilateral hasta por 30 millones de dólares o su equivalente en moneda nacional. Otra perspectiva para el crecimiento de ingresos se tiene con la Venta de Activos muebles e inmuebles que ningún beneficio le prestan a la Administración y que por el contrario tienen un peso fuerte en los gastos de funcionamiento derivado de los costos de administración y funcionamiento que ocasionan. Para este Propósito ya se logro la autorización de la Asamblea Departamental, a través de la Ordenanza No. 004 del 11 de febrero de 2008.

Se realizan acciones ante el gobierno nacional para gestionar recursos ante los diferentes ministerios con el fin financiar diferentes sectores de inversión especialmente vías, agropecuario, educación salud y cultura entre otros. Una vez desarrolladas las gestiones necesarias ante el Ministerio de Hacienda y Crédito Público para la suscripción de Plan de Ajuste Fiscal y Financiero del Departamento, se eliminarán las restricciones para obtener los recursos del crédito para financiar proyectos relacionados con el "Plan Vial Departamental", el cual tiene previsto financiarse con recursos del crédito con la banca multilateral por 70 millones de dólares, para lo cual, la Asamblea Departamental otorgó facultades al Gobierno Departamental. Así mismo, dado que el Gobierna Nacional no viabilizó los recursos correspondientes a la venta de la Represa de Hidropado para atender la red vial del Departamento, el Gobierno Departamental ha contemplado como alternativa la financiación con recursos del crédito interno con la banca nacional hasta por $\$ 150.000$ millones. Con la ejecución de las anteriores acciones se esperan ingresos adicionales para el año de 2008 de $\$ 106.154$ millones, para el año de 2009 de $\$ 106.480$ millones, para el año de 2010 de $\$ 111.924$ millones y para el año de 2011 de $\$ 112.324$ millones.

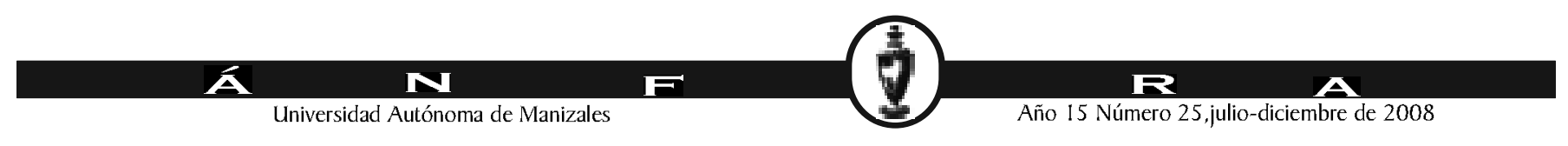




\begin{tabular}{|l|c|c|c|c|c|}
\hline \multicolumn{7}{|c|}{ INGRESOS ADICLIONALES 2008-2001 } \\
(MIIIONES de \$)
\end{tabular}

FUENTE: Secretaria de Hacienda - Dirección de Rentas

\section{Plan Plurianual De Inversiones}

Los recursos disponibles para invertir en el Plan de Desarrollo "Soluciones para la Gente" 2008-2011, asciende a un billón novecientos siete mil treinta millones $\$ 1.907 .030,9$ distribuidos así: $\$ 444.034,4$ millones para la vigencia 2008, $\$ 449.979,6$ millones para la vigencia 2009, $\$ 486.901,1$ millones para la vigencia 2010 y $\$ 526.115,8$ millones para la vigencia 2011.

\section{Fuentes de financiación}

Dentro de las fuentes de financiación para ejecutar el Plan de Desarrollo se encuentran los recursos propios que comprenden ingresos de destinación específica dentro de los cuales figuran la Sobretasa al ACPM, estampillas y otras multas (comparendos), e ingresos corrientes de libre destinación disponibles para inversión, que son todos los demás ingresos que no tienen destinación específica. Para la vigencia 2008-2011, estos recursos ascienden a la suma de $\$ 226.420,7$ millones que representa el $11.9 \%$ de los ingresos totales disponibles para la ejecución del Plan. Otra fuente de financiación del Plan son los recursos provenientes del Sistema General de Participaciones con destinación específica para los sectores de Educación, Salud y Agua Potable y Saneamiento Básico de conformidad con la Ley 715 de 2001 y el CONPES 112 de Febrero 6 de 2008, asciende en total a la suma de $\$ 1.230 .526 .0$ millones para el cuatrienio 2008-2011, transferidos del presupuesto de la Nación y que equivalen al $64.5 \%$ del total de los recursos disponibles para inversión.

Por concepto de Regalías se tiene prevista una inversión de \$334.611.4 millones para el cuatrienio 2008-2011, estos ingresos representan el $17.5 \%$ del total de los recursos a invertir y en donde el $15.5 \%$ de estos recursos es decir $\$ 51.922 .5$ millones serán destinados a financiar lo que se adeuda del Acuerdo de Reestructuración de Pasivos del Departamento como proyecto prioritario de inversión. La diferencia \$282.688.9 millones serán distribuidos de conformidad con lo estipulado en el artículo 14 de la Ley

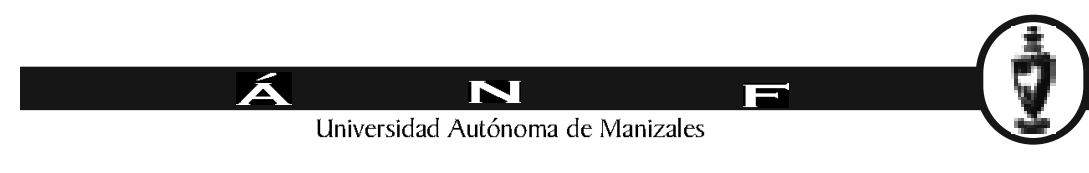


756 de 2002, para ampliar cobertura en Salud, Educación y Agua Potable y Alcantarillado básicamente y en una menor proporción para proyectos prioritarios contemplados en el Plan. Dentro del rubro de otros se encuentran las Rentas Cedidas provenientes del IVA por consumo de cerveza, licores, vinos, aperitivos y similares, impuestos por juegos y apuestas permanentes, premios, loterías foráneas y explotación de la Lotería del Tolima dirigidos al sector de la salud, y recursos transferidos por la Nación para otros programas también de Salud como (Control de enfermedades transmitidas por vectores, estilos de vida saludable para la prevención de enfermedades crónicas y la atención a personas inimputables). También hacen parte de este rubro los recursos de INDEPORTES para el sector Deportivo.

De acuerdo con las proyecciones el rubro de otros asciende a $\$ 115.472,8$ millones que equivale al $6,1 \%$ del total de la Inversión para el cuatrienio 2008 - 2011. Para la vigencia 2008, se incluyó el Superávit del año 2007 equivalente a \$53.320,1 millones de los cuales $\$ 26.094,4$ serán destinados a inversión. Así mismo se tiene previsto para la vigencia 2008, recursos por mayor recaudo de ingresos y por incorporaciones equivalente a $\$ 65.960 .1$ millones de los cuales $\$ 52.645,0$ millones serán destinados a financiar inversión.

\section{Distribución sectorial}

El Plan de Desarrollo "Soluciones para la gente" 2008-2011, se estructuro bajo tres EJES ESTRATÉGICOS: Inclusión Social y Formación del Capital Humano, Competitividad Regional y Ambiente Sostenible. Así mismo se ha considerado unas Políticas Transversales y un Soporte Institucional.

El costo total del plan para el cuatrienio 2008-2011, asciende a un billón novecientos siete mil treinta millones $\$ 1.907 .030,000$, el $60,8 \%$, es decir, $\$ 1.160 .085 .7$ millones corresponde al eje inclusión social y formación del capital humano destacándose la política de educación para todos... un compromiso con la gente; el $20.6 \%$ equivalente a

$\$ 393.343$ millones corresponde a la política salud efectiva para la gente, cuyos ingresos provienen en su mayoría de las transferencias de la nación por el Sistema General de Participaciones. El eje Competencia Regional, dispondrá en el cuatrienio de $\$ 220.740$ millones, equivalente al $11.5 \%$ del costo total del Plan, cifra afectada básicamente por la política adecuación del territorio que comprende la infraestructura y los servicios básicos así como vivienda y desarrollo territorial. Para el eje de ambiente sostenible se tiene previsto $\$ 5.160$ millones es decir el $0.27 \%$. Para las políticas transversales se dejaron recursos por $\$ 5.170$ millones que equivale al $0.30 \%$ del costo del Plan y para soporte institucional $\$ 91.452$ millones que equivale al $4.8 \%$ del costo del Plan para los cuatro años. (ver gráfico 2 )

Para la vigencia del 2008 el total de la inversión es de $\$ 444.034$ millones, para el 2009 el monto de la inversión está proyectada en $\$ 449.980$ millones, para el 2010 en $\$ 486.901$ millones y para el 2011 en \$526.116 millones destacándose el eje Inclusión social y formación del capital humano cuyas políticas son Educación para todos....un compromiso con la gente y Salud efectiva para la gente, con los recursos provenientes del Sistema General de Participaciones. A continuación se presenta el Plan Plurianual de Inversiones que contiene los programas a ejecutar en cada una de las vigencias del Plan de Desarrollo “Soluciones para la Gente" 2008 - 2011, con las diferentes fuentes de financiación.

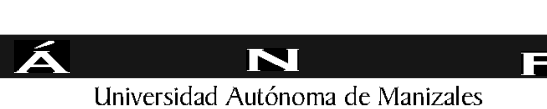




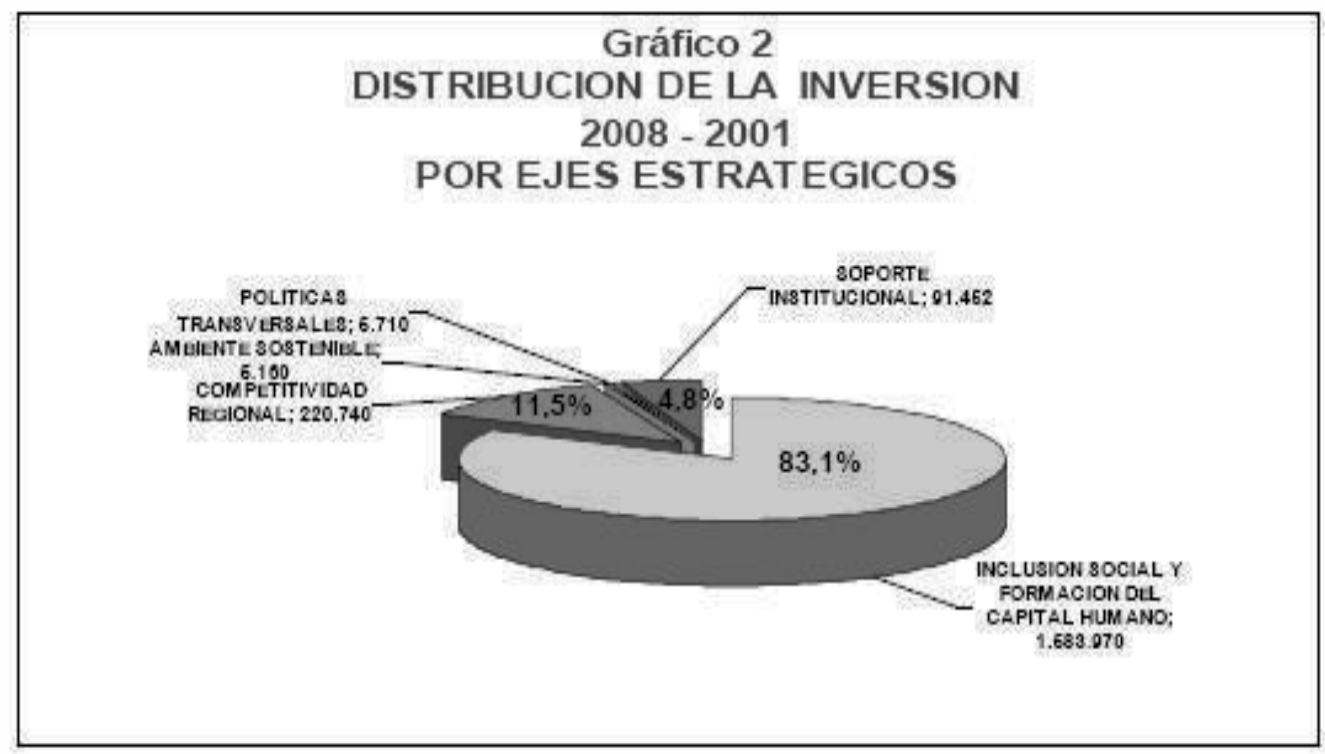

\begin{tabular}{|c|c|c|c|c|c|c|c|c|c|c|}
\hline \multicolumn{11}{|c|}{$\begin{array}{c}\text { TABLA 2 } \\
\text { DISTRIBUCION DE LA INVERSION } 2 \\
\text { (Miliones des) }\end{array}$} \\
\hline CONCEPTO & 2008 & $\%$ & 2009 & $\%$ & 2010 & $\%$ & 2011 & $\%$ & TOTAL & VARIACTO \\
\hline $\begin{array}{l}\text { 1. INCLUSION SOCIAL Y } \\
\text { FORIMACION } \\
\text { CAPITAL HUMANO }\end{array}$ & 372.155 & $83,8 \%$ & 374.499 & $83,2 \%$ & 402.613 & $82,7 \%$ & 434.703 & $82,6 \%$ & 1.583 .970 & $83,06 \%$ \\
\hline $\begin{array}{l}\text { Educación para todos. } \\
\text { Un compromiso con la }\end{array}$ & 273.830 & $61.7 \%$ & 276.687 & $61,5 \%$ & 293.592 & $80,3 \%$ & 315.877 & $80,0 \%$ & 1.160 .086 & $00,83 \%$ \\
\hline $\begin{array}{l}\text { Cutura para la identidad } \\
\text { regional }\end{array}$ & 2.510 & $0,8 \%$ & 842 & $0,2 \%$ & 1.578 & $0,3 \%$ & 1.833 & $0,3 \%$ & 6.782 & $0,35 \%$ \\
\hline $\begin{array}{l}\text { Recreación para la Gente, } \\
\text { deporte masivo y de } \\
\text { Competencia }\end{array}$ & 2.120 & $0,5 \%$ & 2.332 & $0,5 \%$ & 2.565 & $0,5 \%$ & 2.822 & $0,5 \%$ & 9.839 & $0,52 \%$ \\
\hline $\begin{array}{l}\text { Salud efectiva para la } \\
\text { gente }\end{array}$ & 91.209 & $20.5 \%$ & 92.051 & $20,5 \%$ & 100.854 & $20,7 \%$ & 100.429 & $20,8 \%$ & 393.343 & $20,83 \%$ \\
\hline $\begin{array}{l}\text { Gobernabilidad, seguridad } \\
\text { y convivencia }\end{array}$ & 2.386 & $0,5 \%$ & 2.587 & $0.0 \%$ & 4.223 & $0,8 \%$ & 4.743 & $0,9 \%$ & 13.938 & $0,73 \%$ \\
\hline $\begin{array}{l}\text { 2. COMPETITIVIDAD } \\
\text { REGIONAL }\end{array}$ & 40.153 & $9,0 \%$ & 45.897 & $10.2 \%$ & 59.237 & $12,2 \%$ & 75.453 & $14,3 \%$ & 220.740 & $11,58 \%$ \\
\hline Adecuación del Territorio & 32.824 & $7,4 \%$ & 38.897 & $8.6 \%$ & 47.737 & $8,8 \%$ & 00.353 & $11,5 \%$ & 179.811 & $9,43 \%$ \\
\hline $\begin{array}{l}\text { Fortalecimiento } \\
\text { Empresarial }\end{array}$ & 1.140 & $0,3 \%$ & 1.300 & $0,3 \%$ & 2.200 & $0,5 \%$ & 3.200 & $0,6 \%$ & 7.840 & $0,41 \%$ \\
\hline Sectores Productivos & 6.089 & $1.4 \%$ & 5.700 & $1,3 \%$ & 8.300 & $1,9 \%$ & 11.900 & $2,3 \%$ & 32.989 & $1,73 \%$ \\
\hline
\end{tabular}

\section{E N}

Universidad Autónoma de Manizales

\section{Z}

Año 15 Número 25,julio-diciembre de 2008 


\begin{tabular}{|c|c|c|c|c|c|c|c|c|c|c|}
\hline $\begin{array}{l}\text { SOSTENIBLE } \\
\text { AMBIENTE }\end{array}$ & 660 & $0,1 \%$ & 700 & $0,2 \%$ & 1.600 & $0,3 \%$ & 2.200 & $0,4 \%$ & 5.160 & $0.27 \%$ \\
\hline $\begin{array}{l}\text { Gestión ambiental hacia la } \\
\text { conservación del capital } \\
\text { natural y desarrolio social }\end{array}$ & 180 & $0,0 \%$ & 200 & $0,0 \%$ & 600 & $0,1 \%$ & 1,000 & $0,2 \%$ & 1.880 & $0,10 \%$ \\
\hline Gestión del riesgo & 480 & $0.1 \%$ & 500 & $0.1 \%$ & 1.000 & $0,2 \%$ & 1.200 & $0,2 \%$ & 3.180 & $0,17 \%$ \\
\hline $\begin{array}{l}\text { POLITICAS } \\
\text { TRANSVERSALES }\end{array}$ & 760 & $0,25 \%$ & 1.050 & $0,2 \%$ & 1.700 & $0,3 \%$ & 2.200 & $0,4 \%$ & 5.710 & $0,30 \%$ \\
\hline \begin{tabular}{llll|} 
Soluciones para las niñas, \\
los niños y y los \\
adolescentes
\end{tabular} & 410 & $0,1 \%$ & 500 & $0,1 \%$ & 800 & $0,2 \%$ & 1.000 & $0,2 \%$ & 2.710 & $0,14 \%$ \\
\hline Juventud & 100 & $0,0 \%$ & 100 & $0.0 \%$ & 200 & $0,0 \%$ & 300 & $0,1 \%$ & 700 & $0,04 \%$ \\
\hline Grupos étnicos & 150 & $0,0 \%$ & 250 & $0,1 \%$ & 400 & $0,1 \%$ & 500 & $0,1 \%$ & 1.300 & $0,07 \%$ \\
\hline Mujer & 100 & $0,0 \%$ & 200 & $0,0 \%$ & 300 & $0,1 \%$ & 400 & $0,1 \%$ & 1.000 & $0,05 \%$ \\
\hline $\begin{array}{l}\text { SOPORTE } \\
\text { INSTITUCIONAL }\end{array}$ & 30306 & $6,8 \%$ & 27.834 & $6,2 \%$ & 21.751 & $4,5 \%$ & 11.560 & $2,2 \%$ & 91.452 & $4.80 \%$ \\
\hline $\begin{array}{l}\text { Forta ecimiento de la } \\
\text { capacidad de gestión } \\
\text { territorial }\end{array}$ & 30.308 & $6.8 \%$ & 27.834 & $8.2 \%$ & 21.751 & $4,5 \%$ & 11.580 & $2,2 \%$ & 91.452 & $4,80 \%$ \\
\hline TOTAL & 444.034 & $100 \%$ & 449.980 & $100 \%$ & 486.901 & $100 \%$ & 526.116 & $100 \%$ & 1.907 .031 & $100 \%$ \\
\hline
\end{tabular}

Fuente: Depatamento Administrativo de Planeación y Sistemas

\section{Requerimientos Departamentales frente a los ODM}

Sin duda, como se concluyó en el ejercicio precedente de formulación de las Agendas Locales de Desarrollo ya referenciadas para los cinco municipios del norte del Tolima, la primera gran limitación tiene que ver con la insuficiencia de los sistemas de información y, de manera particular, de estandarización y normalización de la información, de manera que sea viable el cruce y análisis de las mismas variables e indicadores para todos los municipios.

Para enfrentar este problema, el Departamento Administrativo de Planeación realiza un ejercicio de análisis de los 47 planes de desarrollo municipal de la vigencia 2008-2011 y organiza diferentes matrices que permitan la lectura de los diferentes componentes y dimensiones presentes en su formulación.

Un primer balance de este ejercicio, es la identificación de proyectos estratégicos de dimensión provincial, que involucran no solo municipios del Tolima sino de departamentos vecinos y que permiten una lectura de visiones de futuro, antes poco visibles en los planes municipales de desarrollo.

En la observación de las capacidades instaladas a nivel municipal, es evidente que el manejo de la información recae generalmente en diferentes dependencias y no existe una unidad de recopilación y de sistematización, con lo que regularmente la entidad departamental o las entidades académicas y técnicas deben realizar una labor de acopio en las mismas para poder proceder a su procesamiento, análisis e inferencias respectivas.

A nivel departamental se ha retomado la labor de la producción del boletín plegable "TOLIMA EN CIFRAS", el cual muestra información departamental e información

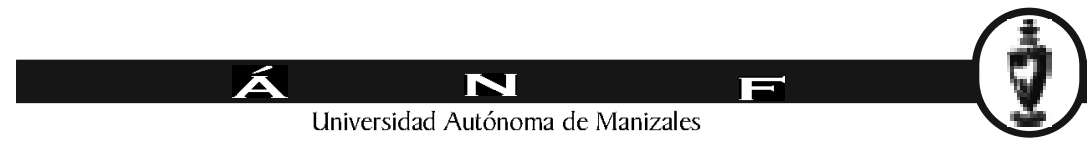


municipal desagregada en las diferentes dimensiones de la vida municipal. Esta labor enfrenta la dificultad de la inconsistencia de la información entre las diferentes fuentes, cuando no la atemporalidad con que la misma se presenta.

El mecanismo previsto para el seguimiento al cumplimiento de las metas relacionadas de manera directa con los ODM deberá ser tomada del proceso mismo de seguimiento a la ejecución del Plan de Desarrollo Departamental y de los diferentes planes municipales de desarrollo.

Con respecto a los actores involucrados en el logro de metas de los ODM resulta claro que la máxima y más directa instancia para ello es el Consejo Departamental de Política Social, al cual el gobierno departamental le ha dedico especial atención a partir de 2007 y tiene continuidad en la administración 2008-2011.

El Departamento deberá considerar la viabilidad de establecer, bajo su directa administración, un Sistema de Información, provisto de las estructuras de bases de datos y sistemas de georeferenciación, que le permitan la permanente conformación, actualización y producción de información para una adecuada y oportuna toma de decisiones. Pero además, como ha sido posible en el Eje Cafetero, participar activamente en la puesta en marcha del Nodo del Sistema de Información Regional SIR, en alianza estratégica con las universidades regionales, la Corporación Autónoma Regional del Tolima, el Gremio Cafetero, Ingeominas, I GAC, SENA, la Unidad Seccional de Fiscalías, los gremios empresariales, las cámaras de comercio, el Banco de la República y otras instituciones con posibilidad de aporte a esta alianza. Con el nivel nacional resulta vital retomar las relaciones permanentes con el Departamento Administrativo de Planeación Nacional y con todos los ministerios e institutos descentralizados. El Tolima e Ibagué no pueden continuar aceptando su marginalidad de las acciones de estas instancias y debe ser preocupación constante de la entidad territorial hacer presencia ante éstas y estar presente en los escenarios nacionales en los cuales pueda ser justificada y resulte relevante su participación.

Todo este proceso deberá situarse en el marco de los propósitos que orientan la conformación de la Infraestructura Colombiana de Datos Espaciales - ICDE.

\section{Estrategias propuestas para la acción.}

Una estrategia central ha sido pública y profusamente divulgada en cada uno de los 47 municipios del departamento por el gobierno departamental: la concertación, más allá de las colectividades políticas y de los intereses particulares. Lemas como "Lo público es sagrado" y "Soluciones para la gente", expresan esta visión y propósito incluyente del ejercicio de buen gobierno.

Además del Consejo Departamental de Política Social, se promueven pactos y alianzas estratégicas que involucran al sector estatal, al sector privado y a las comunidades, en un esfuerzo visible y reconocido de generar confianza en lo público estatal.

Un vehículo, como estrategia, ha sido el mantenimiento de los "conversatorios" sobre el Plan de Desarrollo, los cuales no solo se realizaron en la fase de consulta para la formulación del Plan sino que se mantienen como espacios para hacer seguimiento público al cumplimiento de las metas del Plan en sus diferentes ejes, políticas, programas, subprogramas y proyectos.

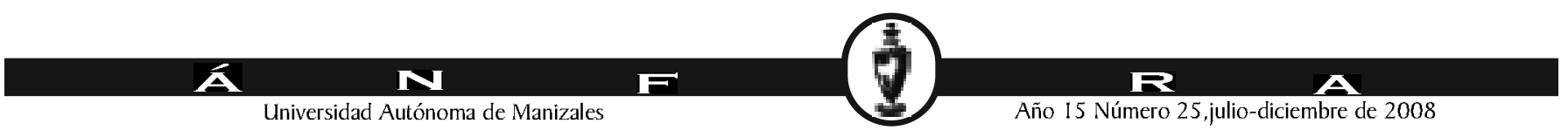


Si bien las metas propuestas por los ODM y sus indicadores, corresponden en términos generales a condiciones medias de pobreza, exclusión y marginalidad en sociedades dependientes en los continentes de América, Asia y África, es pertinente, como lo ha aconsejado el mismo PNUD, realizar los ajustes necesarios a las condiciones particulares que en cada país, y de manera particular, en cada región, se aproximen más a la problemática genérica que les dieron origen.

Se indica que si bien se pueden mantener los 8 objetivos, como referentes válidos y ordenadores de un ejercicio de buen gobierno y de construcción de políticas públicas, nuevos objetivos podrían ser adicionados y consecuentemente otros indicadores, o incluso, algunos de los 48 indicadores base, podrían ser modificados y/o sencillamente reemplazados, en respuesta a las particularidades territoriales en que se esté interviniendo o se proponga intervenir.

En todo caso este primer ejercicio a escala regional constituye una apuesta valiosa e inédita que permitirá, por primera vez en Colombia y seguramente en Latinoamérica, realizar una lectura regional sobre la relación planes de desarrollo departamental ODM, facilitando no solo la normalización de variables e indicadores sino la identificación de problemas relativos, fundamentalmente, a la precariedad de nuestros sistemas de información local, regional y nacional, lo que al mismo tiempo dificulta la realización de ejercicios de análisis de la realidad latinoamericana asociada a los ODM.

\section{Bibliografía consultada.}

DANE. Censo 2005.

PNUD - TOLIPAZ (2005), Agendas Locales de Desarrollo. Municipios de Mariquita, Fálan, Venadillo, Alvarado y Piedras. Departamento del Tolima. ESPINOSA, Rico Miguel Antonio, Consultor.

DNP (2005), “METAS Y ESTRATEGIAS DE COLOMBIA PARA EL LOGRO DE LOS OBJ ETIVOS DE DESARROLLO DEL MI LENIO - 2015". Bogotá, D.C.

DEPARTAMENTO DEL TOLIMA (2008), Plan de Desarrollo "Soluciones para la agente 2008-2011".

DEPARTAMENTO DEL TOLIMA (2007), POLITICA PÚBLICA Y AGENDA. PARA LA I NTERNACIONALIZACION DEL TOLIMA. Documento de Trabajo. Asesoría de Asuntos Internacionales. Mayo de 2007.

DEPARTAMENTO DEL TOLI MA (2007), Ordenanza 009 de 2007.

MONROY Marisol (s.f.), UNA APROXIMACIÓN CRÍTICA A LA NOCIÓN DE DESARROLLO EN LA ORGANIZACIÓN DE NACIONES UNIDAS: LOS OBJ ETIVOS DE DESARROLLO DEL MI LENI O. México. Universidad Nacional Autónoma de México.

MURILLO Xatli. (2008), Cartilla para municipalizar los Objetivos de Desarrollo del Milenio. Formulación de Planes de Desarrollo 2008-2011 con enfoque de construcción de paz. Manizales. Litocreativa, Ed.

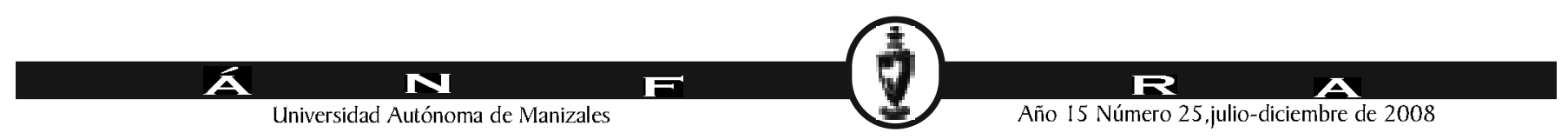

